\title{
Feature-oriented regional modeling of oceanic fronts
}

\author{
Avijit Gangopadhyay ${ }^{\mathrm{a}, *}$, Allan R. Robinson ${ }^{\mathrm{b}}$ \\ ${ }^{a}$ Department of Physics and School for Marine Science and Technology, University of Massachusetts \\ Dartmouth, 285 Old Westport Road, North Dartmouth, MA 02747, USA \\ ${ }^{\mathrm{b}}$ Department of Earth and Planetary Sciences, Division of Engineering and Applied Sciences, Harvard \\ University, 29 Oxford Street, Cambridge, MA 02138, USA
}

Received 8 May 2001; received in revised form 29 March 2002; accepted 1 April 2002

\begin{abstract}
This paper outlines some important aspects of modeling oceanic fronts in the context of featureoriented regional modeling for the deep sea and the Global Coastal Ocean. Previously developed forms of feature models for different types of fronts are presented in a generalized approach. The large-scale meandering frontal systems such as the Gulf Stream, Kuroshio and Brazil current can be represented by velocity-based feature models. Buoyancy forced coastal water mass fronts, such as the coastal currents, the tidal fronts, plume fronts, dense water fronts and inflow/outflow fronts can be represented by a generalized parameterized water mass feature model. The interface region of the deep ocean and the coastal region can be modeled by a melding of two water masses along and across a prescribed isobath in the form of a shelf-break front. Initialization and/or updating fields for a regional dynamical model can then be established in association with other available synoptic data sets via a feature-oriented strategic sampling approach for forecasting and dynamical balances. Example simulations from the western north Atlantic (WNA) and the strait of Sicily region are presented in support of the applicability of this approach for the Global Coastal Ocean. Simulations in the strait of Sicily region with fronts, eddies and background climatology help provide a perspective on dynamical processes in this region. Application of this methodology for rapid assessment of any regional ocean, based on limited data and resources is now possible.

(C) 2002 Elsevier Science B.V. All rights reserved.
\end{abstract}

Keywords: Coastal region; Feature-oriented regional modeling; Oceanic fronts

\section{Introduction and background}

During the last three decades, there has been significant advancement of our accrued knowledge and understanding of oceanographic phenomenology, circulation and variability

\footnotetext{
* Corresponding author.

E-mail addresses: agangopadhya@umassd.edu, avijit@umassd.edu (A. Gangopadhyay).
} 
in regional oceans. This has been possible due to technological advances in numerical modeling capabilities, in the availability of highly efficient computing platforms, in multi-platform instrumentation capabilities with both in the sea and from different satellites, as well as in model-data assimilation and integration methodologies. It is now our understanding that each oceanic region, however unique they may be in their individual behavior, consists of a number of 'generic' or 'common' characteristic synoptic circulation structures and water masses. These synoptic entities or 'features', when put together in the background climatology of a particular region, interact and evolve together to generate the combined circulation variability due to different regional set-up of multi-scale processes, bathymetry, boundaries and forcing due to winds and buoyancy. A regional basin may include a set of multi-scale features such as large-scale meandering currents and fronts, basin-scale and sub-basin-scale gyres, mesoscale eddies and vortices. A coastal region may include circulation structure features such as mesoscale buoyancy-driven (water mass) fronts, upwelling fronts and submesoscale eddies and fronts.

Advances have been made in applying such knowledge-based 'feature models' for regional simulations and operational forecasting. Specifically, the studies by Robinson et al. (1988, 1989), Spall and Robinson (1990), Hurlburt et al. (1990), Fox et al. (1992), Glenn and Robinson (1995), Hurlburt et al. (1996), Cummings et al. (1997), Gangopadhyay et al. (1997), and Robinson and Glenn (1999) have applied the 'feature modeling technique' for use in nowcasting, forecasting and assimilation of various in situ (XBT, CTD) and satellite (GEOSAT, Topex/Poseidon) observations in the western north Atlantic (WNA). A significant focus was on the meanders and rings of the Gulf Stream system, and some of these operational systems have shown significant success compared to persistence in predicting the behavior of the ring-stream system on 1-2-week period (Glenn and Robinson, 1995; Gangopadhyay and Robinson, 1997). It is also noteworthy that the application of 'feature models' for naval application has recently been implemented operationally by the Royal Navy (Heathershaw and Foreman, 1996) and has also been developed for global application in a coupled ocean-atmosphere climate prediction mode (Johns et al., 1997).

It is important to recognize the role of fronts in describing the regional circulation. From a regional modeling and prediction perspective, identification of a front may be associated with different processes relevant to the local regional dynamics and phenomenology. For example, a large-scale Gulf Stream meandering frontal system also defines the boundaries of unique water masses, which in turn, defines the boundary of the basin and sub-basin-scale gyres in a synoptic state (see Gangopadhyay et al., 1997). There are also circular fronts, e.g. eddies and rings which have unique water masses. With the availability of satellite data, the unique signature of fronts is now identifiable in the gradients of sea surface temperature (SST), sea surface height and sea surface color. At the same time, evolution of a water mass frontal system in a regional coastal ocean may dominate the variability. Thus, a collective use of satellite sensors may be effectively translated into frontal detection in a particular region for initialization and updating. So, modeling fronts as 'features' in the initial and subsequent updating stages is crucial for achieving a consistent predictive capability of the regional system. The authors (Gangopadhyay et al., 2002) recently developed a feature-oriented regional modeling and simulation (FORMS) methodology particularly for Gulf of Maine and Georges Bank (GOMGB) coastal region, but with a generic viewpoint. 
The focus of this paper is to present the importance and generality of feature modeling of oceanic fronts in the context of synoptic regional modeling. This opens the possibility of applying them for regional modeling of the Global Coastal Ocean. A list of different kinds of fronts that are observed in the eastern boundaries of the world ocean is presented in the first table of Hill et al. (1998) and discussed by many in The Sea (Robinson and Brink, 1998). These include: upwelling fronts, equatorial fronts, water mass fronts, plume fronts, coastal current fronts and shelf-break fronts. The western boundary regions are dominated by large-scale meandering currents such as the Gulf Stream, Kuroshio, Brazil current, Somali current, and east Australian current (Loder et al., 1998). Note that the large-scale wind-driven current transport and its interaction with the adjacent gyres play important roles in the dynamics of the western boundary current fronts (in addition to their role as the boundary of two distinct water masses); while the constituent water masses and buoyancy forcing primarily contribute to the formation and maintenance of the coastal and water mass fronts (Hill et al., 1998; Church et al., 1998). We present here generalizations of the frontal feature models developed for the deep Gulf Stream meander and ring (GSMR) region and the shallow GOMGB region intended to be applicable towards any region of the world oceans.

Generally, most nowcasting and forecasting dynamical model simulations need specification for both water mass $(t, s)$ and circulation $(u, v, w)$ fields. The deep ocean transport feature models are developed on the basis of the circulation $(u, v)$ fields. The regional modeling system uses a known streamfunction-water mass relationship to derive the water mass $(t, s)$ fields (Gangopadhyay et al., 1997). Similarly, the regional coastal feature models based on temperature and salinity properties are first geostrophically adjusted to derive a consistent baroclinic velocity component. Furthermore, additional barotropic flow fields are supplied, if known externally, or by adjusting the level of no motion in a short (1-2 days) model simulation (Gangopadhyay et al., 2002). These procedures ensure that the water masses and circulation fields are consistent for dynamical simulations.

This paper first overview result to date for the WNA coupled deep sea: coastal region. Additionally, the generic 'FORMS' concept is illustrated by constructing a synoptic forecast system for a new region, namely, the strait of Sicily. The developed feature models for the WNA deep and coastal regions are first summarized in Section 2. The dynamical implications of the feature-oriented regional modeling approach are laid out in Section 3. Generalized feature models of velocity-based fronts, temperature/salinity fronts, and shelf-slope fronts (SSF) are presented in Section 4. Additional features such as eddies and gyres, which can be thought of as circular fronts, are also presented in this section. The feature-oriented approach to create synoptic three-dimensional initialization and updating fields for WNA is briefly described in Section 5. The general approach is then illustrated via a simulation example in the strait of Sicily in Section 6. Section 7 concludes this study.

\section{Western north Atlantic feature-oriented regional modeling}

An example regional modeling set-up is presented in Fig. 1 for the WNA. A two-way nested modeling methodology has been set-up for this region (Haley and Lozano, personal communication) for research and operational purposes. These include the littoral ocean observation and prediction system (LOOPS) (Robinson et al., 1998) and a real-time 


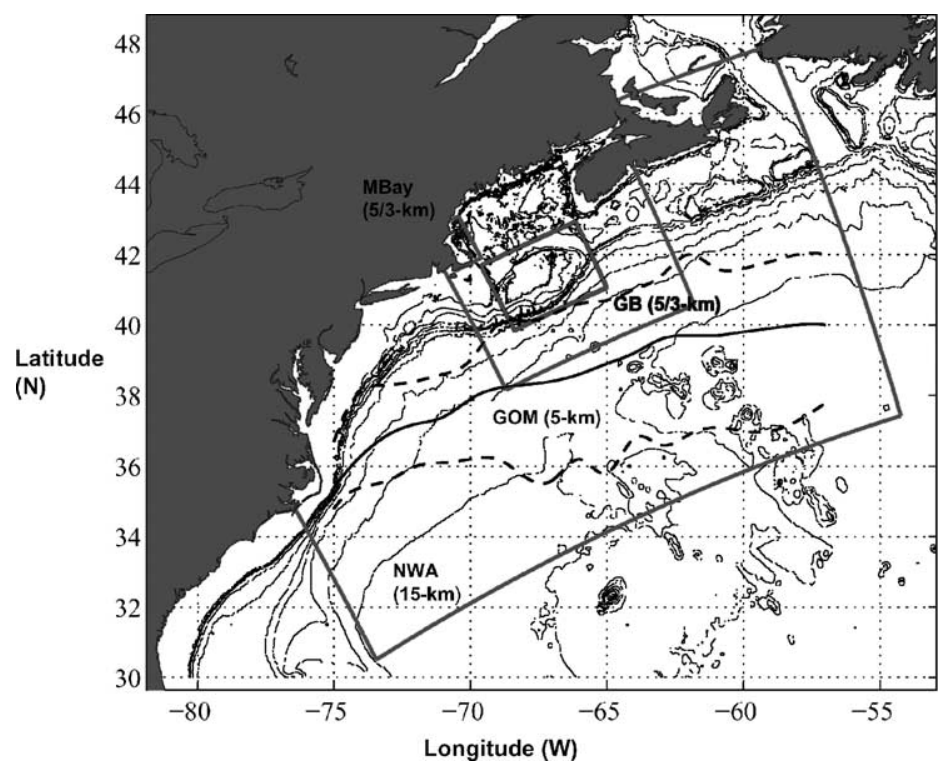

Fig. 1. Multi-scale-nested modeling domains for the WNA. The NWA domain has a horizontal resolution of $15 \mathrm{~km}$ with triple-nested domains in: Gulf of Maine ( $5 \mathrm{~km}$ resolution), Georges Bank $(5 / 3 \mathrm{~km})$ and Massachusetts Bay $(5 / 3 \mathrm{~km})$. Feature-oriented initialization and updating helps in transferring information between such regions through multi-scale circulation structures, which exist, evolve and interact over these domains in a dynamical model.

demonstration of concept for an advanced fisheries management information system (AFMIS) (Robinson et al., 2000; Brown et al., 2001). This triple-nested version is utilized in this paper to demonstrate the concept of multi-scale feature-oriented regional modeling in a coupled deep sea coastal ocean environment.

The deep GSMR region has the large-scale meandering Gulf Stream front, which interacts with the sub-basin-scale gyres and generates mesoscale eddies, the deep western boundary current and other mesoscale and submesoscale transients. A schematic of the multi-scale features of the regional circulation is shown in Fig. 2. The circulation in the coastal GOMGB region is associated with features such as the buoyancy-driven Maine coastal current (MCC), Georges Bank anticyclonic frontal circulation system, the basin-scale cyclonic gyres (Jordan, Georges and Wilkinson), the deep inflow through northeast channel and the shallow outflow via the great south channel. A schematic of the surface circulation of this coastal region with the features identified is presented in Fig. 3(a), while Fig. 3(b) shows different processes and the topographic pathways that the coastal features tend to follow. The characteristic set of multi-scale features in these two adjacent deep and coastal regions are listed in Table 1. The difference between them can be related to the differences in their oceanographic set-up. In addition to processes that govern the deep regional dynamics (large-scale wind-driven, barotropic and baroclinic instabilities, meandering and eddy-mean flow interaction), significant variability in the shallow region is determined from water mass formation, topography, fresh water influence, tides, winds and heating/cooling. 


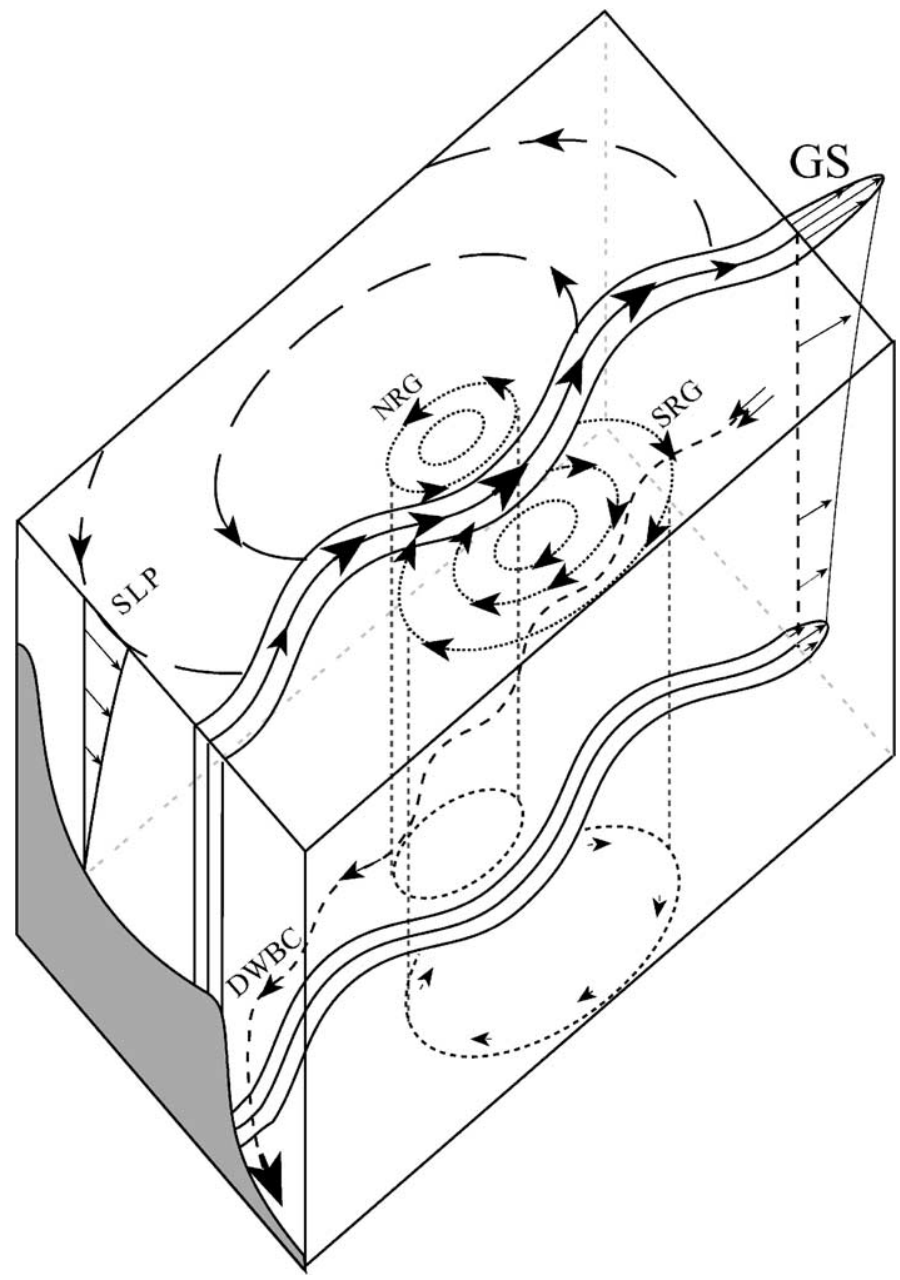

Fig. 2. A multi-scale circulation cartoon for the GSMR region (adapted from Gangopadhyay et al., 1997). The large-scale meandering of the Gulf Stream results in mesoscale eddies while interacting with the sub-basin-scale gyres (NRG and SRG). The deep western boundary current flows along the $3400 \mathrm{~m}$ isobath and crosses under the Gulf Stream near Cape Hatteras to flow further southward.

In the southern part of the GOMGB region and the northern part of GSMR, lies the slope water region where the prevalent flow is to the southwest. However, the warm core rings (WCR) are imposed on this background circulation, which affect the regional circulation considerably. This salty slope water region creates a water mass boundary with the fresher GOMGB circulation system along the narrow region close to the $100 \mathrm{~m}$ isobath, which is known as shelf-break or the SSF. In the feature-oriented approach outlined in Gangopadhyay et al. (2002), the coastal region and the deep region are melded together along and across the SSF following Sloan (1996) and Lermusiaux (1999a,b). The methodology for melding is interlaced with the design of a feature model for the SSF. 

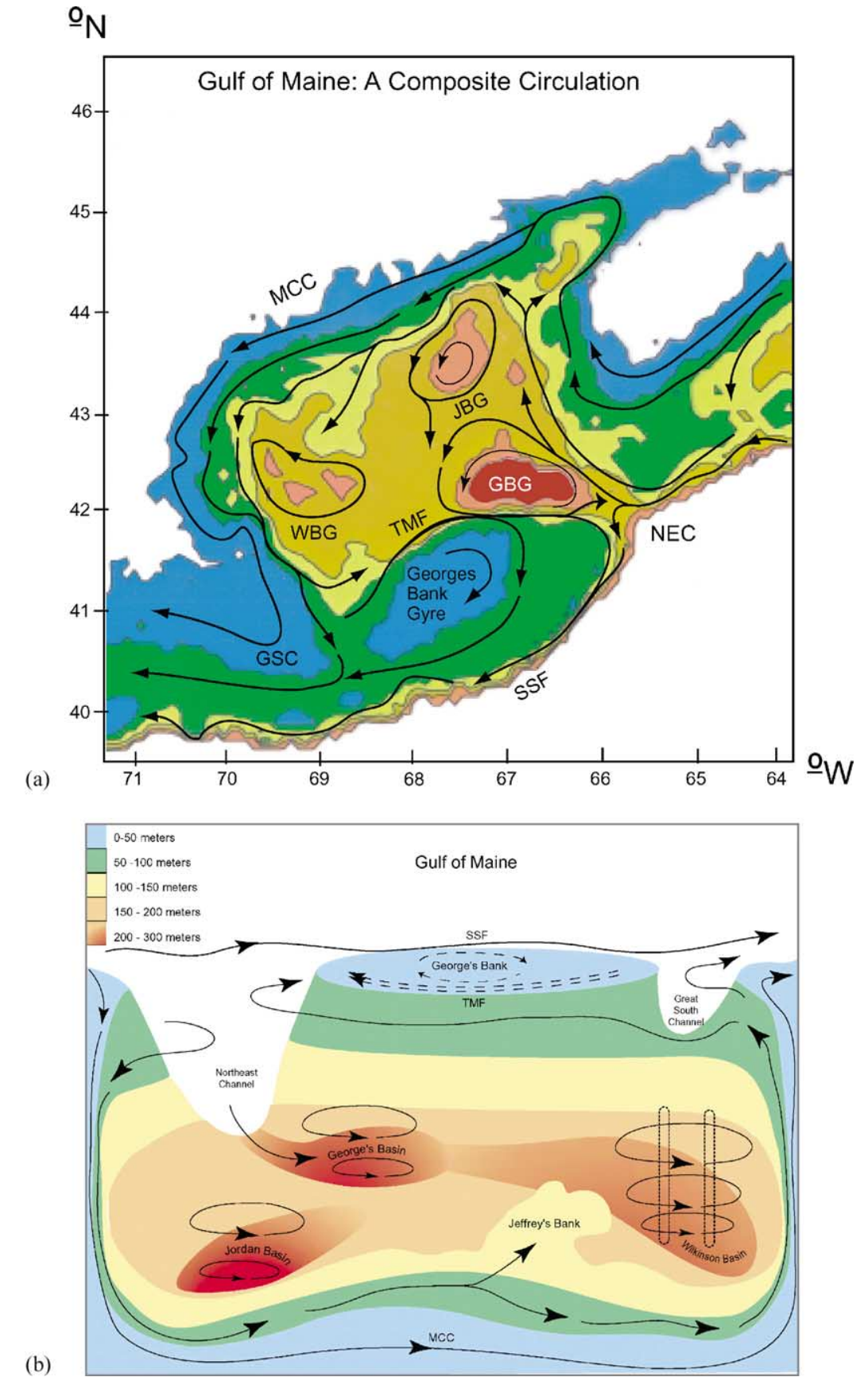

Fig. 3. (a) A schematic of circulation features in the Gulf of Maine: GSC, great south channel; SSF, shelf-slope front; NEC, northeast channel; GBG, Georges basin gyre; TMF, tidal mixing front; WBG, Wilkinson basin gyre; MCC, Maine coastal current; JBG, Jordan basin gyre. (b) A three-dimensional bathymetric perspective of the regional circulation features. The basins are the three deep regions in the interior gulf. The vertical mixing region is predominantly in the Wilkinson basin. 
Table 1

Circulation features in GSMR (deep) and GOMGB (coastal) regions

\begin{tabular}{|c|c|c|c|c|c|c|c|}
\hline $\begin{array}{l}\text { Deep region } \\
\text { (GSMR) }\end{array}$ & Gulf Stream & $\begin{array}{l}\text { Deep western } \\
\text { boundary current }\end{array}$ & Warm core rings & Cold core rings & $\begin{array}{l}\text { Northern } \\
\text { recirculation } \\
\text { gyre }\end{array}$ & $\begin{array}{l}\text { Southern } \\
\text { recirculation } \\
\text { gyre }\end{array}$ & $\begin{array}{l}\text { Slope water } \\
\text { circulation }\end{array}$ \\
\hline $\begin{array}{l}\text { Coastal region } \\
\text { (GOMGB) }\end{array}$ & $\begin{array}{l}\text { Maine coastal } \\
\text { current and } \\
\text { GSC outflow }\end{array}$ & $\begin{array}{l}\text { Georges Bank } \\
\text { anticyclonic circulation } \\
\text { and associated tidal } \\
\text { fronts }\end{array}$ & Shelf-slope front ${ }^{\mathrm{a}}$ & $\begin{array}{l}\text { Wilkinson basin } \\
\text { circulation }\end{array}$ & $\begin{array}{l}\text { Jordan basin } \\
\text { gyre }\end{array}$ & $\begin{array}{l}\text { Georges basin } \\
\text { gyre }\end{array}$ & NEC inflow \\
\hline
\end{tabular}

NEC: north east channel; GSC: great south channel.

${ }^{\text {a }} \mathrm{SSF}$ is the boundary region between the deep and the coastal region. 


\section{Dynamical implications of feature-oriented regional modeling}

Dynamics is essential for the FORMS concept. The individual features and their interactions are dynamically adjusted in a general physical dynamical ocean model. Parametric sensitivity studies and dynamical model tuning are essential. The dynamically adjusted and evolving system is then studied to understand regional dynamical processes. It forms the basis of a regional operational forecast system.

In considering a region, the important features of the regional circulation must be first identified and parameterized on the basis of past synoptic observations and dynamical understanding. For example, the Gulf Stream 'feature model' developed by Gangopadhyay et al. (1997) was designed to approximate the observed potential vorticity distribution across the stream. Second, the kinematically linked system of feature models and background climatology is dynamically adjusted. For the Harvard ocean prediction system (HOPS) (Lozano et al., 1996; Robinson, 1999), 'geostrophic' or short-term (1-3 days) 'quasi-geostrophic' dynamical balances are used for generating dynamically adjusted initialization and updating fields for the primitive equation model. A dynamically adjusted and parameterized system provides for studying model sensitivities to different processes in the region. For example, Robinson and Gangopadhyay (1997) determined that the ability to maintain the integrity of the Gulf Stream for long-term simulations (3 months without data assimilation) was more dependent on the diffusion in the numerical domain, than on the effect of boundary conditions. They also obtained a dynamically consistent set of parameter ranges for which the Gulf Stream simulations yielded realistic wave growth and ring interaction behavior for different seasons. Specifically, the 'feature model' parameters used for a lower (higher) transport carrying stream during fall-winter (spring-summer) corresponding to the slower (faster) phase-speed and smaller (larger) growth rate range were quantified based on the numerical model's dynamical behavior. Such dynamical analyses are the building blocks of the FORMS methodology that should be independently performed in every new regional set-up for the Global Coastal Ocean.

In short, FORMS in a regional ocean is developed in stages. The empirical-analytical design formulation of the three-dimensional velocity and water mass structures of a feature is called the 'feature model'. Examples of velocity-based feature models are found in Robinson et al. (1988) and Gangopadhyay et al. (1997) for the GSMR region. Examples of water mass structure-based temperature/salinity feature models (TSFMs) are found by Sloan (1996), Lozano et al. (1996) and Gangopadhyay et al. (2002). Feature models can be used collectively for generating a synthesis of three-dimensional synoptic circulation system. Calibration of a synthesized parameter set involves four-dimensional dynamical simulations for validating the synoptic and statistical behavior of the regional model set-up (Robinson and Gangopadhyay, 1997; Gangopadhyay and Robinson, 1997). Moreover, for creating a three-dimensional synoptic initialization or updating/assimilation fields, the synoptic features are melded with background climatology by a strategic feature-oriented sampling and objective analysis methodology (see Lozano et al., 1996; Gangopadhyay et al., 2002).

Assimilation and subsequent dynamical adjustment of the 'features' allows for dynamical analyses of simulations that otherwise would be impossible to attain. Robinson et al. (1988) have shown this to be case for Gulf Stream meanders and rings and their 
interactions (propagation, formation and re-absorption). This was characterized by Robinson and Gangopadhyay (1997) for the same region by dynamical calibration. For GOMGB region, after the dynamical adjustment, the Jordan basin gyre was found to be stable, but the gyres on the Wilkinson and Georges basins were seen to develop multi-lobe configurations (Gangopadhyay et al., 2002).

There is an important distinction between 'feature models' and 'feature-oriented regional modeling'. The former is applicable for a particular oceanographic circulation structure or water mass entity, e.g. fronts, eddies, plumes, lenses, gyres, currents, etc. It deals with the question 'how does one model a particular structure in its synoptic state?' The concept of 'feature-oriented regional modeling' focuses more on the region; it deals with 'dynamical synthesis of regional features in the local set-up including their mutual interactions'.

\section{Generic feature modeling of fronts, eddies and gyres}

In this section we overview the feature models of different kinds of fronts in a generalized manner, so that they can be applied to many different regions of the world ocean. The velocity-based representation of the western boundary currents and similar fronts are presented first. The buoyancy-driven water mass fronts, which are of particular importance in coastal regions, are modeled by temperature and salinity structures. A special role is played by the shelf-break or SSF, which often lies between the deep and the coastal regions along the continental shelf. It is modeled as water mass front, using a melding formulation of temperature and salinity properties from the slope and shelf regions. Similar fronts occur in different world oceans, and a preliminary list of observed fronts in the deep and coastal ocean regions is provided in Table 2 .

\subsection{Large-scale meandering fronts}

The regional oceans in the coastal margins on the western boundaries of the world oceans are naturally influenced by their interaction with the major western boundary currents and their associated gyres and instabilities, which result in mesoscale eddies. Example regions include: (i) the northeastern shelf of North America, being affected by large-scale meandering of the GSMR region dynamics; (ii) the northwestern region of the Pacific Ocean, namely, the Sea of Okhotsk and the Japan/east sea (Preller and Hogan, 1998), the China seas (Jilan, 1998) including the south China sea, the east China sea and the Yellow Sea, which are affected by the large-scale meandering currents off of the Kuroshio and Oyashio system; (iii) the western south Atlantic continental shelf (Piccolo, 1998) affected by the Brazil-Malvinas confluence region; and (iv) the Arabian Gulf (Sheppard and Dixon, 1998) being affected by the seasonal appearance of the great whirl and Socotra gyre associated with the monsoon reversal of Somali current in the Indian Ocean (Shetye and Gouveia, 1998). These western boundary currents are results of the large-scale wind-driven circulation, and carry a large transport of warm water toward the polar regions (Royer and Stabeno, 1998). Under these currents are thermohaline flows like the deep western boundary currents. Together, they comprise the global conveyor belt (Gordon, 1986). 
Table 2

Feature model classification of oceanic fronts

\begin{tabular}{|c|c|c|}
\hline Region & $\begin{array}{l}\text { Deep (boundary currents, } \\
\text { meanders and jets) }\end{array}$ & $\begin{array}{l}\text { Coastal (water mass fronts, upwelling fronts, } \\
\text { transition regions, tidal fronts) }\end{array}$ \\
\hline Western north Atlantic & $\begin{array}{l}\text { Gulf Stream, deep western } \\
\text { boundary current }\end{array}$ & $\begin{array}{l}\text { Maine coastal current, Georges Bank } \\
\text { tidal fronts, shelf-slope front }\end{array}$ \\
\hline Eastern north Atlantic & $\begin{array}{l}\text { Azores current, Canary current, } \\
\text { Portugal current }\end{array}$ & Upwelling fronts in northwest Africa \\
\hline Western Pacific & $\begin{array}{l}\text { Kuroshio, deep western boundary } \\
\text { current }\end{array}$ & $\begin{array}{l}\text { Yellow Sea coastal current, Korean coastal } \\
\text { current, ECSCC, SCSCC, Taiwan warm } \\
\text { current, Tsushima current }\end{array}$ \\
\hline North Pacific & $\begin{array}{l}\text { North Pacific current, California } \\
\text { current system }\end{array}$ & $\begin{array}{l}\text { Alaskan coastal current, Alaskan stream, } \\
\text { Prince William sound circulation system }\end{array}$ \\
\hline South Pacific & $\begin{array}{l}\text { East Australian current, Humbolt } \\
\text { current }\end{array}$ & Upwelling fronts in central Chile \\
\hline South Atlantic & Brazil current & $\begin{array}{l}\text { Angola-Benguela front, Benguela } \\
\text { upwelling system }\end{array}$ \\
\hline $\begin{array}{l}\text { Northwest European } \\
\text { shelf and Bering Sea }\end{array}$ & $\begin{array}{l}\text { Labrador current, north } \\
\text { Atlantic current }\end{array}$ & $\begin{array}{l}\text { Norwegian current, tidal mixing fronts, } \\
\text { Celtic Sea shelf-break front }\end{array}$ \\
\hline $\begin{array}{l}\text { Equatorial pacific } \\
\text { (similar in equatorial } \\
\text { Atlantic) }\end{array}$ & Equatorial current systems & Upwelling fronts, NEC, NECC, SEC, SECC \\
\hline Southern ocean & Antarctic circumpolar current & $\begin{array}{l}\text { Agulhas retroflection current, Weddell } \\
\text { front, Antarctic circumpolar shelf front }\end{array}$ \\
\hline Indian Ocean & $\begin{array}{l}\text { Somali current, Agulhas current, } \\
\text { western India undercurrent }\end{array}$ & $\begin{array}{l}\text { North Indian coastal current, east } \\
\text { African coastal current }\end{array}$ \\
\hline
\end{tabular}

This list is not exhaustive. It is intended to show a representative set of frontal features selected from the regional synthesis papers presented in The Sea, vol. 11, which contains 31 chapters on different regional coastal oceans around the world.

These currents or deep ocean frontal systems interact with surrounding sub-basin-scale gyres, through injection or extraction of mass flow. Such consideration led Gangopadhyay et al. (1997) to develop a velocity-based feature model for these currents. The generalized form is provided in Eq. (A.1) in Appendix A, along with parameters for other features.

The major frontal characteristics in this parameterization are represented by: (1) the cross-frontal structure, $\gamma(y)$; (2) the baroclinic structure given by the first term of Eq. (A.1) with vertical shear parameterized as $\varphi(x, z)$ and amplitude given by $\left(U^{\mathrm{T}}-U^{\mathrm{B}}\right)$; and (3) the barotropic component represented by the bottom velocity $\left(U^{\mathrm{B}}\right)$. A schematic from Gangopadhyay et al. (1997) is presented in Fig. 4(a) to illustrate the above representation of this kind of frontal system.

There are two important aspects in the design of Eq. (A.1), that relates to the generalization of this formulation for meandering currents such as the Gulf Stream, the Kuroshio, the deep western boundary current and similar fronts. First, the horizontal distribution function, $\gamma(y)$ can be modeled by an analytical, empirical, or a combination parameterization based on available knowledge of the system. For example, the Gulf Stream was modeled by Gangopadhyay et al. (1997) via an asymmetric Gaussian-empirical combination based on the Halkin and Rossby (1985) data set. Preliminary investigation into Kuroshio observations by Teague et al. (1994) (see 10th figure of their paper) suggests a strongly asymmetric 


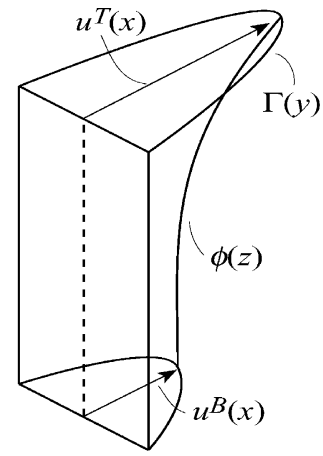

(a)

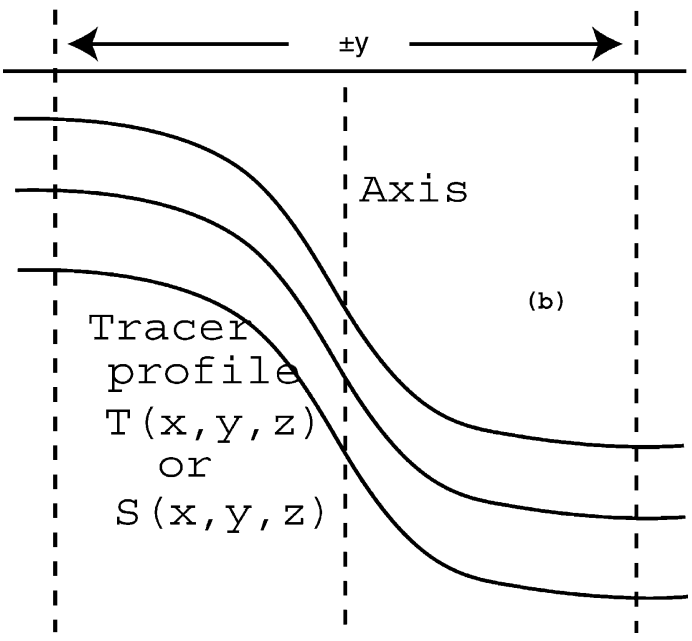

Fig. 4. (a) Velocity-based feature model parameters, which can be used for transport dominated frontal regions such as the Gulf Stream, Kuroshio, Brazil current and others (see Eq. (A.1) for the formulation). (b) Water mass $(T-S)$ feature model parameters for buoyancy dominated currents, fronts and flows, such as described in Eq. (A.2).

distribution for $\gamma(y)$. Moreover, a recent study by Sainz-Trapaga and Sugimoto (2000) showed two velocity maxima at the first crest of the Kuroshio front. Feature modeling of Kuroshio for nowcasting, forecasting and process studies might be developed in the future based on velocity and potential vorticity considerations. The deep western boundary current for the WNA was modeled as an analytical Gaussian distribution by Gangopadhyay et al. (1997). The exact distribution of the deep current in western Pacific is not yet fully developed (Hallock et al., 1996; Hurlburt et al., 1996) and a Gaussian distribution may be adopted as a first approximation.

The second factor (within the curly brackets) in Eq. (A.1) is representative of the baroclinic/barotropic flow component distribution in the vertical. The parameters in this term, specifically, the top and bottom axis velocities, and the non-dimensional shear profile $(\varphi(x$, $z)$ ) together define the alongstream variation of transport of such currents. The interaction 
with the surrounding gyres can be modeled by mass exchange/extraction methodology as prescribed by Gangopadhyay et al. (1997) via barotropic and baroclinic components, by tuning the three parameters in this second factor. For the Kuroshio system, it is apparent that the different modes (large-meander, straight path and short-meander) of its path can be effectively parameterized by selectively varying these parameters, while maintaining a kinematic (mass-conserving) balance.

The water mass structures across the deep sea free inertial jets can be rather complex. For the Gulf Stream, the high transport jet core is situated at the boundary between two distinct water masses (slope and Sargasso). Additionally, the core of the stream carries several different water masses from outside of this region, which originated during its inertial and wind-driven regime further south. This complex interplay between the velocity-based feature models and the stream's water mass properties was characterized by a regional water mass model, which was developed by Spall and Robinson (1990) and later modified by Lozano et al. (1996). Similar situations must be anticipated in other regions of the world oceans.

\subsection{Coastal water mass fronts}

The circulation in any coastal region can be described in terms of its response to winds, tides and buoyancy forcing (Brink, 1998a,b). While the barotropic response to winds and tides have been studied for a long-time (Brown, 1998) and operational models are available for tides and storm-surges in many different parts of the Global Coastal Oceans (Simpson, 1998); the response to the buoyancy forcing of individual regions needs to be understood in detail via numerical (Haidvogel and Beckmann, 1998) and observational studies. Our present day understanding of the processes occurring in the coastal ocean due to buoyancy forcing which include heating/stirring systems, regions of freshwater influence (ROFI), dense water inflow/outflow, and basin-exchange flows are discussed from a dynamical perspective by Hill (1998). In general, buoyancy loss in shallow coastal regions creates dense water pools, shelf-break fronts, dense plumes and lenses; while buoyancy input forms structures such as tidal mixing fronts, shelf-break fronts, and ROFIs, which include river plume fronts, coastal fronts, and coastal currents.

For the purpose of feature modeling, these fronts can be parameterized by their water mass properties, i.e. temperature and salinity profiles. Furthermore, a different class of fronts in the coastal ocean is the upwelling fronts, which occur consistently over many coastal regions around the world. It is possible to link the density gradient of an upwelling front to the water mass characteristics for appropriate vertical velocity, wind stress and isopycnal uplifting combination in a proper dynamical framework; however that is not the focus of this paper. Here, we present a generalized parameterization of a wide range of water mass fronts and overview their application in different individual regions.

The three-dimensional synoptic temperature (salinity) structures can be represented by normalized empirical shear in the vertical and empirical-analytical horizontal distribution across a water mass current/front/flow feature (see Fig. 4b). Their adapted functional form is given by Eq. (A.2) in Appendix A.

The dimensional temperature/salinity profile, $T_{\mathrm{a}}(x, z)$ is represented by a combination of the surface $\left(T_{0}(x)\right)$ and bottom $\left(T_{\mathrm{b}}(x)\right)$ values of temperature/salinity at the axis of the 
feature, and $\Phi(x, z)$ which is the normalized vertical temperature/salinity profile, with a value of unity at top and zero at the bottom. This representation allows for a combination of water masses for a particular feature through selection of different values of temperature and salinity at the surface, and the bottom as well as by the structure of $\Phi(x, z)$.

Clearly, the alongstream variations of surface and bottom temperature/salinity representation $(\alpha(x, z))$ in this feature model allow for the effects of river runoff, buoyancy flow influx and other anomalous water masses. Moreover, the second term in the first equation allows for a choice of $\Gamma(y)$, which, if chosen as a step-function, would allow for uniform core temperature or salinity signatures (such as plumes, or pools) within a buoyancy-driven front. Similarly, the along-stream variation of $\Phi(x, z)$ allows one to represent the effects of vertical mixing, branching off of currents and joining of frontal systems in an objective manner. One example usage of $\Phi(x, z)$ is the representation of the minimum temperature layer for MCC at mid-depth. The rationale for choosing a generalized form of $\Phi(x, z)$ in Eq. (A.2) is two-fold: (i) it allows parameterization of branching over topographic features or due to buoyancy input from rivers, as a combination of different water masses by changing the vertical structure alongstream; (ii) it allows for representation of effects of seasonal processes that occur in the gulf, such as vertical mixing in the winter in the western GOM, i.e. by constraining $\Phi(x, z)=1$ during the wintertime, one can impose vertical mixing/homogeneity of water column for the MCC. A detail description of MCC feature model can be found in Gangopadhyay et al. (2002). Similar coastal currents around the coastal ocean are Norwegian coastal current, Alaskan coastal current, and many others, which are listed in Table 2.

For the purpose of representing the circulation on the northern edge of Georges Bank, Gangopadhyay et al. (2002) developed a synoptic feature model of the tidal (mixing) front. Generally, for a tidal mixing front (Simpson and Hunter, 1974; Horne et al., 1989) the density structure is dominated by the temperature field over the bank and by the contribution of salinity field at deeper levels over the side of the bank. This variable contribution is well simulated by the frontal tracer representation given by Eq. (A.2) through the term $(\alpha(z))$. Similar tidal (mixing) fronts are observed notably in the northwest European shelf and other areas (see Table 2).

Gangopadhyay et al. (2002) gave an implementation of this formulation (Eq. (A.2)) for the southern flank of Georges Bank. This front is represented by a frontal boundary between the well-mixed water on the bank in the north and salty slope water to the south. Proper choices of the across-slope gradient of temperature and salinity defined the frontal system for all seasons.

An example of a dense water inflow is the entering of the warm and saline waters of the slope region through the bottom of the northeast channel. The feature model representation of this inflow is similar to Eq. (A.2) with $\Phi(x, z)=\Phi(z)$ and with different $\alpha$ value on different side of the axis. This was chosen to effectively allow the modeling of the steep salinity gradient on the Scotian shelf side and the sharp temperature gradient on the near side of Georges Bank. According to the analysis of Ramp et al. (1985), the warmest and mostly salty waters were found in the mid-channel region. Similar constructs could be used to design the plume fronts or other dense water pools in the ROFIs in coastal ocean.

Another major aspect of the frontal systems is that the frontal temperature and salinity parameters change downstream (examples are Gulf Stream, Atlantic ionian stream (AIS), 
southern ocean frontal system as shown by Belkin and Gordon, 1996). This requires a flexible parameterization of the water mass structure of the frontal system, which was modeled here by $\alpha(x, z)$ in Eq. (A.2). However, new approaches in terms of Lagrangian and spatial empirical orthogonal functions (Warn-Varnas, personal communication) should also be explored for possible implementation to achieve a globally applicable alongstream variation parameterization.

\subsection{The deep-to-coastal interface: shelf-slope front}

The SSF is a transition between the cold, fresh shelf water and warm, saltier slope water extending from Cape Hatteras (north of the Gulf Stream) through mid-Atlantic bight and beyond the northeast channel. The surface signature of the SSF is one of the most readily observable features from satellites, which were analyzed by Halliwell and Mooers (1979). Wright (1976) analyzed the interaction of the front with bottom topography and determined that $80 \%$ of the time, the front remained within $16 \mathrm{~km}$ of the $100-\mathrm{m}$ isobath. The SSF is primarily density dependent (Allen et al., 1983; Sloan, 1996; Loder and Gawarkiewicz, 1998), with salinity dominating the density constituents.

A TSFM adaptation, which was originally developed by Sloan (1996) and used for assimilation studies in coastal region (Robinson et al., 1998), is briefly described here. Specifically, the SSF is modeled as a melding region of two water masses (shelf and slope) along and across the shelf-break region. A schematic of the SSF is presented in Fig. 5(a). The elements of the SSF includes: defining the mean location at surface from satellite observations, defining the isotherm and isohaline corresponding to the mean location at the bottom (Wright, 1976; Mountain, 1991), the slope (Chapman and Gawarkiewicz, 1993; Houghton

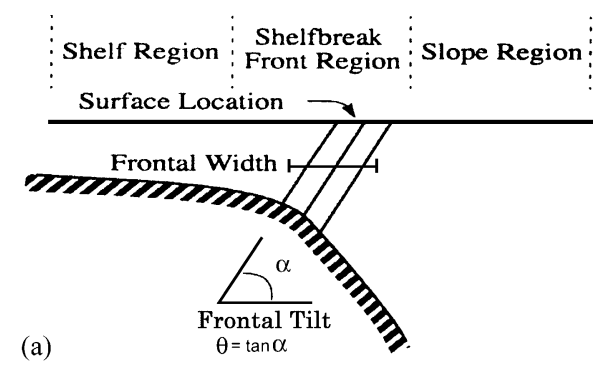

Analytical Water Mass Melding

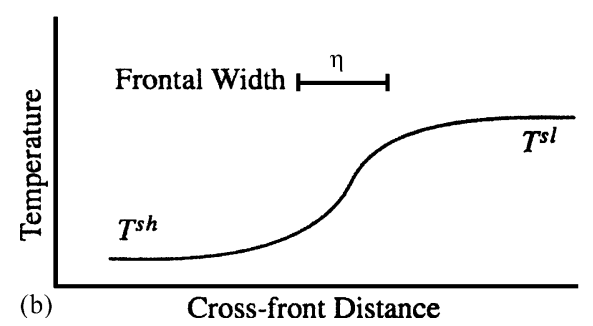

Fig. 5. Schematic representation of (a) shelf-break feature model front and (b) analytical water mass $(T-S)$ melding from shallow to deep regions. 
et al., 1988, 1994), the width (Behrens and Flagg, 1986) and the melding function. A recent comprehensive description of the climotology of the shelf-break front from southern flank of Georges Bank, through the region south of Nantucket Shoals and off the coast of New Jersey is given by Linder and Gawarkiewicz (1998).

For example, the shelf water temperature and salinity (say, $T^{\mathrm{sh}}$ ) may be available from the coastal domain objective analysis of GOMGB multi-scale feature model fields and climatology (for details see Gangopadhyay et al., 2002) or from available data sets. In addition, the slope water $T, S$ fields (say, $T^{\mathrm{sl}}$ ) may be available from similar sources, i.e. Gangopadhyay et al. (1997) or available synoptic data sets. Implementation of a SSF feature model is then carried out by a combination of the above two fields. Following Sloan (1996), the resulting $T-S$ fields are determined by the Eq. (A.3) in Appendix A, which invokes a hyperbolic tangent melding function across the width of the front. A schematic representation of the melding function is shown in Fig. 5(b).

\subsection{Eddy and gyre feature models}

In addition to fronts, two other important features of regional circulation system need to be discussed in the context of FORMS. These are the mesoscale eddies and basin-to-subbasin-scale gyres. The eddies can be formulated by adapting the generalized version of equations developed for the fronts (A.1 and A.2) in polar co-ordinate system (i.e. $r-\theta-z$ in place of $x-y-z$ ). Such an adaptation for the velocity-based Gulf Stream rings was formulated by Gangopadhyay et al. (1997) and is listed in Eq. (A.4) in Appendix A.

A simple model for the temperature- and salinity-based feature models for the warm or cold core rings is developed by a combination of contribution from the core tracer value and that from the background tracer value. The exponential combination is presented in Eq. (A.5) in Appendix A. The dynamical implications for this selection lie in: (1) the core temperature fades out at a distance of about five times the mesoscale radius $\left(R_{0}\right)$ and (2) the background temperature starts fading in at and continue beyond the mesoscale radius.

Similarly, for a basin-scale or sub-basin-scale gyre, the circular eddy formulation can be extended to adapt to an elliptical framework as was done by Gangopadhyay et al. (1997). The velocity-based elliptical gyre formulation is presented in Eq. (A.6) in Appendix A. Application of this formulation was presented in Gangopadhyay et al. (1997) study for the southern and northern recirculation gyres in the WNA, as well as in the slope water gyre.

Extension of the elliptical gyre implementation for the temperature and salinity feature models is done simply by assuming the tracer distribution as a function of $(r, \theta, z)$, where the tracer amplitude is only depth-dependent, modulated by a horizontal (radial) distribution dependent on $r$ (and similar to the exponentials for eddy TSFM); and varying in the azimuth direction $(\theta)$ in a prescribed manner. The mathematical expression is presented in Eq. (A.7) in Appendix A. Note that in a feature-oriented regional modeling system, the placement of synoptic sections for feature model profiles dictate the choice of azimuth function to be a delta function with a value of unity along specific directions. For example, in Gulf of Maine system, the three sub-basin-scale gyres in the Wilkinson, Jordan and Georges basins are represented by TSFMs along the major and minor axes of their mean elliptical signature. 
On the other hand, the circular signature of ionian shelf vortex (ISV) in the strait of Sicily region was exploited to place the synoptic sections of the TSFMs along two orthogonally placed diametric cuts through this eddy. These will be detailed later in the simulations that are presented in Section 6.

\section{Regional modeling with application to the western north Atlantic}

In order to develop a feature-oriented scheme for modeling and simulating a regional ocean, one needs to start by identifying the important features that are to be resolved, simulated and studied. This process involves looking at the past data and analysis studies in the region of interest. Once the features of importance and interest are identified, one needs to identify data sets (both synoptic and climatology) that are representative of the features and its associated processes and phenomenology of interest. Such data sets are used to develop the representative feature models and interaction parameters between surrounding features which are further calibrated through numerical model simulations (see Robinson and Gangopadhyay, 1997). A calibrated set of feature models are then used for nowcasting and forecasting the regional dynamics via four-dimensional FORMS.

In this section, we present an example of feature-oriented modeling for the WNA utilizing the frontal feature models presented in the previous section. Note that, fronts do not exist in isolation, there are surrounding water masses and other mesoscale and submesoscale features, which, together with the fronts, collectively define the three-dimensional state of the regional ocean. Thus, it is necessary to construct a three-dimensional synoptic initialization field with all features (including fronts) which will be used for simulation via numerical models. We will overview the WNA in the remainder of this section and illustrate the application of the idea in the strait of Sicily in the next section.

\subsection{Constructions of synoptic realizations}

In order to generate the three-dimensional initialization fields in a regional deep-coastal modeling domain like Gulf of Maine (see Fig. 1) for a primitive equation model such as the HOPS, a six-step procedure is followed. These are: (i) strategic feature-oriented sampling of $T-S$ fields; (ii) creating shelf OA $T-S$ fields; (iii) creating the deep OA fields; (iv) adjusting the shelf and slope OA fields to bottom topography; (v) melding the shelf and slope OA fields through the SSF; and (vi) generating the equivalent barotropic streamfunction for the numerical dynamical model (for details see Gangopadhyay et al., 2002). Also note that, although this procedure is developed for HOPS, it is equally applicable for other dynamical models, e.g. for those using finite element algorithms (Lynch et al., 1996; Lynch, 1999; Hannah et al., 2001) or for other terrain-following models (Blumberg and Mellor, 1987; Haidvogel et al., 2000).

An example of the feature-oriented approach is presented here for the coastal GOMGB region. First, the temperature and salinity feature model fields are selectively sampled along and across the important features as shown in Fig. 6. The dots in Fig. 6 are the locations chosen for sampling the important features of circulation for this region (see Fig. 3). Previous synoptic sections along and across feature locations are extremely useful in developing the 


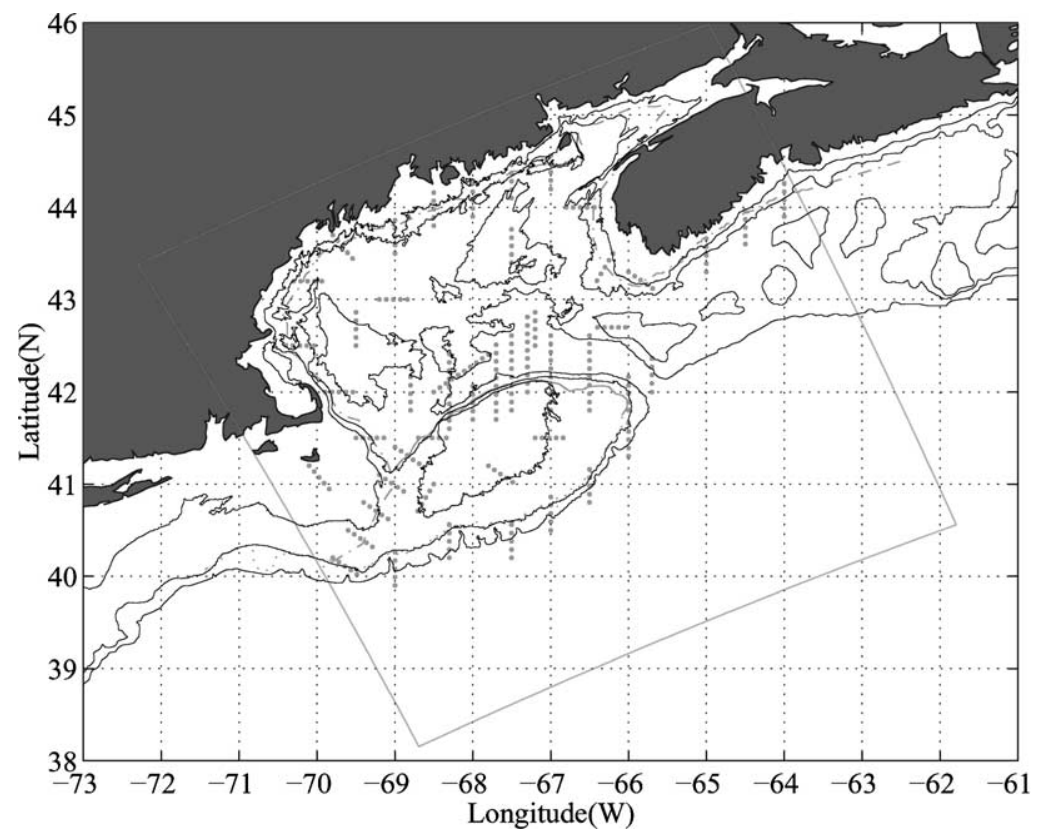

Fig. 6. Feature-oriented sampling strategy for initialization and updating of numerical models in the GOMGB region. The dot marks are pseudo CTD locations where temperature and salinity profiles are generated based on feature models. These are strategically selected along and across circulation features such as MCC, tidal mixing front, SSF, northeast channel inflow, great south channel outflow and the three basins: (1) Wilkinson; (2) Jordan; and (3) Georges.

strategic locations and designing the feature models. This strategic feature-oriented sampling ensures the presence of synoptic structures in the initialization and updating fields for nowcasting and forecasting. Second, these sampled fields are treated as pseudo-CTD observations and objectively analyzed (Carter and Robinson, 1987; Watts et al., 1989; Bisagni, 1991) with appropriate background seasonal climatology in the coastal shelf domain. The resulting shelf OA field for temperature and salinity (see Fig. 7) thus combines the synoptic structures in a background of available climatology, appropriate for nowcasting and forecasting.

Geostrophic computation of dynamic height field from the $T-S$ fields yields the baroclinic velocity components, which are interpolated to terrain-following levels. The interpolated velocity field is vertically integrated to determine the barotropic velocity. The curl of the barotropic velocity field then generates the barotropic vorticity. Dirichlet boundary conditions for the transport streamfunction are obtained by integrating the normal component of the barotropic velocity through the boundary, subjected to the constraint of no net transport through the boundaries. Finally, the transport streamfunction is constructed by solving a Poisson equation forced by the barotropic vorticity with these boundary conditions. The resulting fields are then used as the initial conditions or updating fields for primitive equation model simulations. 


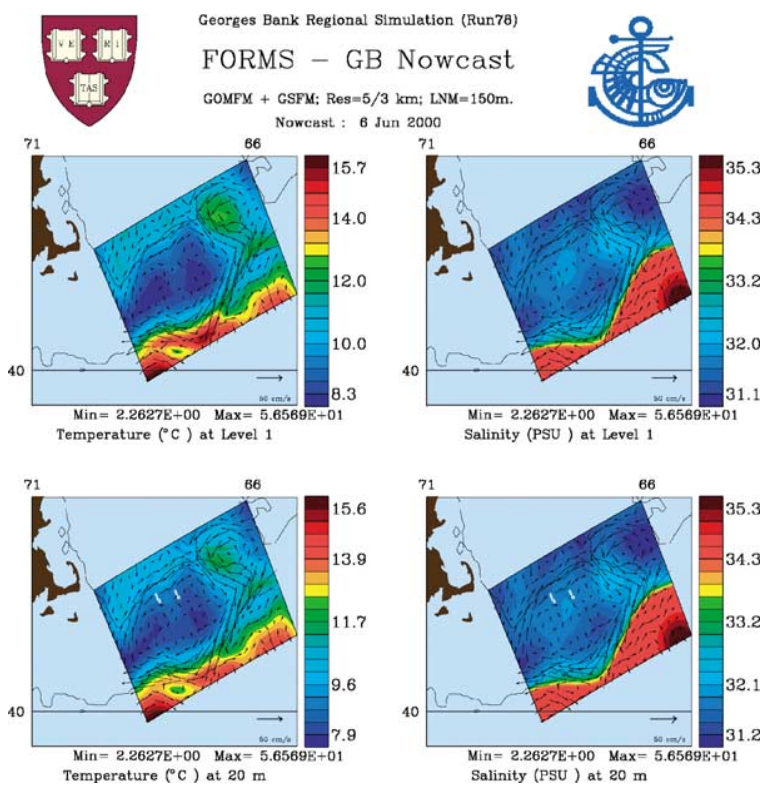

Fig. 7. Initialization fields of temperature (upper left) and salinity (upper right) at the surface for Georges Bank domain simulation. Similar fields are shown in the bottom panels at a depth of $20 \mathrm{~m}$. Superimposed velocity vectors are also shown at the corresponding levels. Note the anticyclonic circulation on the bank is already set-up via feature models at this fine resolution.

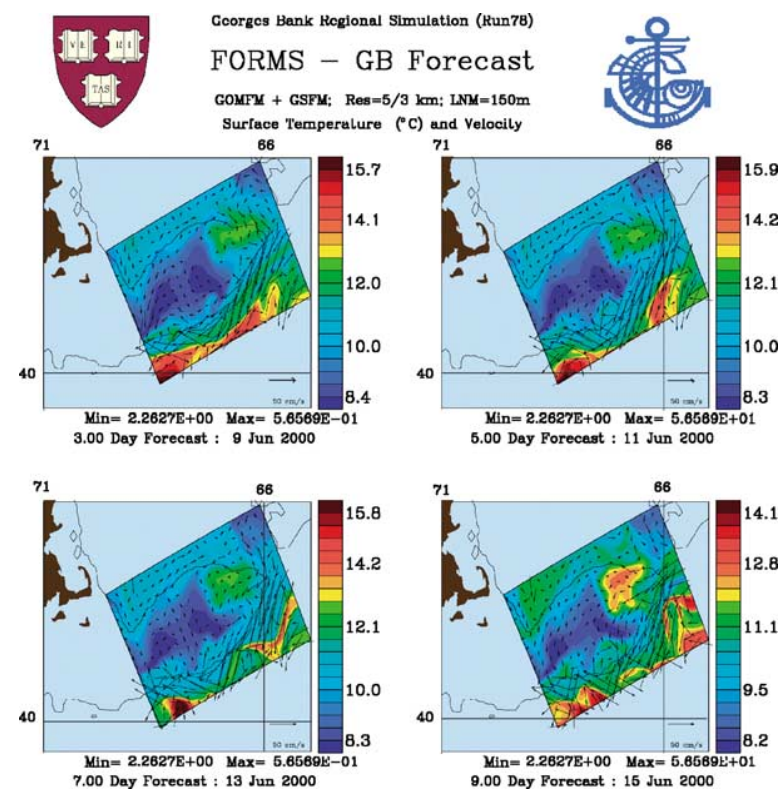

Fig. 8. Three-day simulation fields of temperature (upper left) and salinity (upper right) at the surface for Georges Bank domain. Similar fields are shown in the bottom panels at a depth of $20 \mathrm{~m}$. Superimposed velocity vectors are also shown at the corresponding levels. Note the robustness of the anticyclonic circulation around the bank, and tightness of the tidal front on the northern side of the bank. Note also the maintenance of the SSF in its entirety during the simulation. 


\subsection{An example regional simulation on Georges Bank}

As mentioned earlier, the coastal regions of GOMGB contains the continental slope region, and affected by the slope water circulation and WCR from the GSMR deep-water region. It is thus necessary to meld the shelf OA fields of temperature and salinity with those from the synoptic GSMR feature model fields following Gangopadhyay et al. (1997). This melding methodology utilizes the SSF feature model described in Section 2 (for further details see Gangopadhyay et al., 2002).

A set of multi-scale simulations were carried out in the nested domains in Fig. 1 for the WNA, GOMGB domains during a real-time operational exercise during the spring of 2000 (Robinson et al., 2000). We present one example simulation for Georges Bank region as it represents the highly resolved tidal front. Fig. 7 (upper panel) shows the initial fields of temperature and salinity at the surface for 6 June 2000. Note the clear synoptic signature of the tidal mixing front on the northern side of Georges Bank in the superimposed velocity vectors. Also note the realistic realization after melding of the synoptic Gulf Stream region with the regional coastal circulation fields along and across the SSF. The deeper fields at $20 \mathrm{~m}$ are shown in the bottom panel of Fig. 7.

A preliminary forecast was carried out without wind forcing, however with tidal mixing. The temperate evolution at the surface for days 3, 5, 7 and 9 are presented in Fig. 8 (clockwise) with superimposed velocity fields. The mesoscale activity along the shelf-break generates realistic shingles and plumes interacting with the southern edge of Georges Bank. The anticyclonic circulation around Georges Bank is well maintained through day 7, after which the western boundary region is affected by the temperature plume advected through great south channel region. The initial robust signature of the cyclonic eddy (left panels of Fig. 7) in the NEC maintains itself through day 5. Beyond then, its evolution is affected by persisted eastern boundary conditions (see bottom panels of Fig. 8).

The integrity of the tidal (mixing) front is maintained throughout the 10-day simulation, which shows that the combination of tidal mixing effects and barolcinicity is reasonably simulated by this parameterization in the numerical model.

\section{Application to the strait of Sicily}

The strait of Sicily is an interesting oceanographic region, which interconnects the enclosed eastern Mediterranean with the semi-enclosed western Mediterranean. A synoptic description of the current structure and hydrography of eastern Mediterranean has been recently summarized by Theocharis et al. (1998). A model- and data-based synthesis was performed first by Robinson et al. (1991) which identified the major circulation components and processes of the eastern Mediterranean including the strait of Sicily. Grancini and Michelato (1987), Manzella et al. (1988) and De Agostini (1998) have studied the water masses and their exchange through the strait in detail. More recently, Robinson et al. (1998) and then Lermusiaux and Robinson (2001) have summarized the features of dominant mesoscale variability, circulation patterns and dynamics in this region, based on model-data assimilative simulations for the August-September of 1996. In this study, we use their analysis to develop a feature-oriented modeling system for the strait of Sicily. 


\subsection{A synoptic feature-oriented kinematical set-up}

A schematic of the major circulation features in the strait of Sicily is shown in Fig. 9(a) in the background of a synoptic SST image. These are: the AIS, the adventure bank vortex (ABV), the Maltese channel crest (MCC), the ionian shelf-break vortex (ISV), the bifurcation region of the AIS and the Messina rise vortex (MRV) which have been recently identified by Lermusiaux and Robinson (2001). Fig. 9(b) shows the locations of available temperature and salinity profiles from GDEM (generalized digital environmental model; Teague et al., 1990) climatology. The monthly averaged temperature, salinity and resulting flow fields from such climatology will of course be very smooth and will lack the synopticity that is present in reality as evident from the SST image in Fig. 9(a). In the study of Lermusiaux and Robinson (2001), the rapid response forecast analysis was based on a very extensive high-resolution survey data set collected by ships, and thus did not use any 'feature model'. These ship tracks and stations are shown in Fig. 9(b). Their analysis was based on data-based initialization and progressive assimilation of data sets as they were being collected during the survey in real-time.

We present our approach by using a small subset of the data from the study of Lermusiaux and Robinson (2001) to develop 'feature models' for the three important circulation features, the AIS, the ABV and the ISV. Only three synoptic sections were selected as representative of the AIS cross-stream structure near the entrance to the strait as shown in Fig. 9(b). These sections are marked near the entrance of the strait of Sicily channel between Sicily and Libya. The feature model for AIS was adapted using Eq. (A.2) for a water mass front. The rationale for water mass front is based on the analysis by Warn-Varnas et al. (1999). The gradients were determined from the available section data (Lermusiaux and Robinson, 2001). The temperature gradient varies from $\{-0.5 \mathrm{C} / 20 \mathrm{~km}\}$ at the surface to $\{-0.2 \mathrm{C} / 20 \mathrm{~km}\}$ at a depth of $300 \mathrm{~m}$. The salinity gradient was chosen to be uniform at all depths with a value of $0.25 \mathrm{ppt}$ across the half width of the front, which was determined to be $50 \mathrm{~km}$. The selected temperature and salinity profiles of the feature model AIS are shown in Fig. 10 (a) and (b).

The path of the AIS axis is shown in Fig. 9(c), which shows the bifurcation region near $16^{\circ} \mathrm{E}$. The 'AIS feature model' temperature and salinity structures are laid along and across the frontal axis as indicated in this figure by station locations. Note that this methodology allows the modeler to place suitable stations near the boundaries of the domain to properly simulate the current inflow and outflow into and out of the region. Fig. 9(c) also shows the sub-region (marked 'climatology') where temperature and salinity profiles from the

Fig. 9. (a) Schematic of AIS from Lermusiaux and Robinson (2001). Cartoon of the summer surface circulation features identified by Robinson et al. (1998) for the strait of Sicily region (De Agostini, 1998). It is superimposed on the satellite SST distribution for 25 August 1996 (Saclantcen). The path of the AIS is shown with its bifurcation region. Also shown are other features of circulation: ABV, MCC and ISV. (b) Locations of in situ data collection stations during AIS96 survey. Note the three sections marked as 'AIS FM sections' near the entrance of strait of Sicily. Only these sections were used for developing the AIS frontal feature model. (c) Feature-oriented regional modeling scheme for the strait of Sicily. Shown are the along- and cross-stream locations of synoptic profiles for the AIS front, the ABV eddy and the ISV eddy. 
(a)
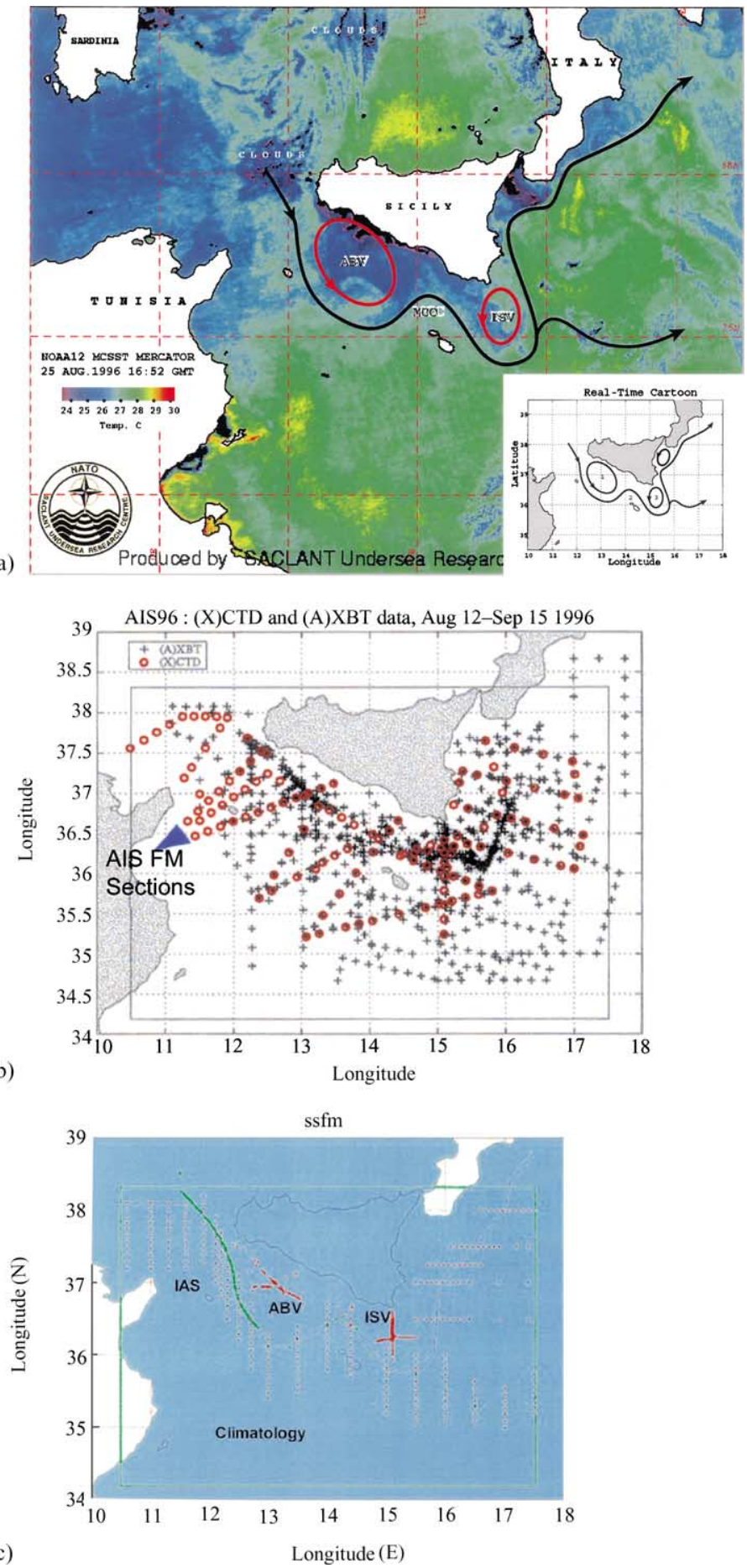
(a) AIS FM Temperature structure

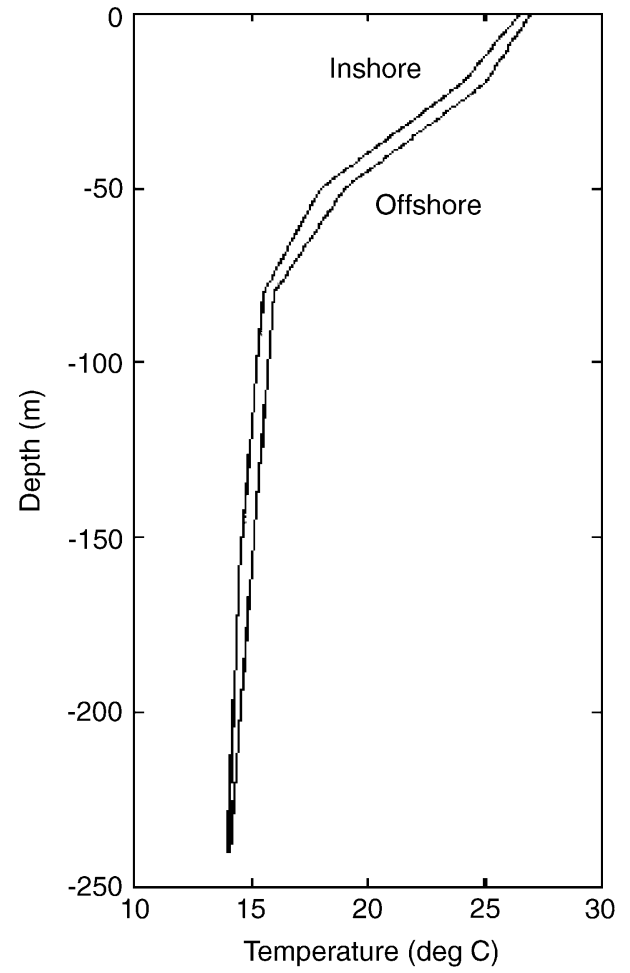

(b) AIS FM Salanity structure

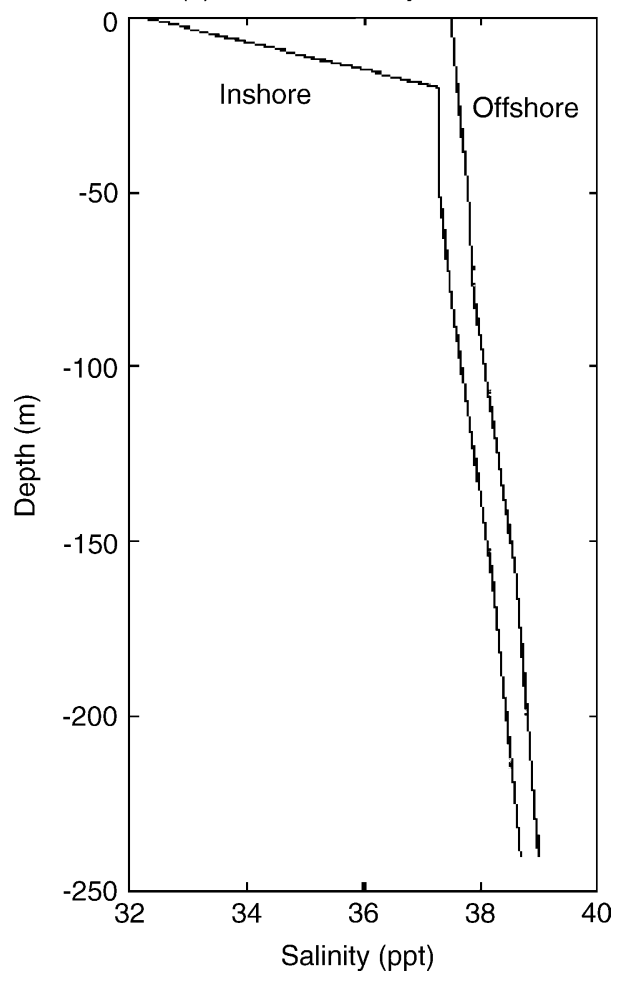

Fig. 10. Adopted feature model temperature (a) and salinity (b) profiles for the AIS. The inshore and offshore profiles are based on only three sections shown in Fig. 9(b).

GDEM climatology, were used as the supplementary background field for the Nowcast. The temperature and salinity fields from the full climatology were objectively analyzed for the month of August and the resulting initialization fields are shown in Fig. 11(a). Note the lack of synopticity in temperature and the weakness of circulation (velocity) fields, which undermines their stand-alone usage in synoptic initialization or updating mode.

Using the feature-oriented methodology, the collection of FM and climatological profiles in Fig. 9(c) were objectively analyzed to produce a synoptic initialization field, which is shown in Fig. 11(b). It is clear that the synopticity of the fields in Fig. 11(b) is much more realistic than in those of Fig. 11(a). Such synoptic realizations can be generated routinely, once the path of AIS is determined from satellite or otherwise and can be used for nowcasting and forecasting exercises. Note that only a subset $(<200)$ of the total of $1000+$ available observational stations (from the study of Lermusiaux and Robinson, 2001) were used here to develop the initialization field. Such economic sampling strategy would be very useful for the rapid environmental assessment exercises (Robinson and Sellschopp, 2001) routinely carried out by NATO and others. 
A major aspect of synoptic initialization is to maintain compatibility between the vertical structures of temperature and salinity for the synoptic features and that of the background climatology. Incompatibility between the synoptic and climatological water masses leads to spurious and unwanted local flow regions resulting from anomalous water mass distribution.

A comparison between climatology (Fig. 11(a)) and a synoptic initialization via featureoriented methodology (Fig. 11(b)) presents some important aspects of using FORMS in this region. The structures and strengths of the AIS inflow in the strait, the bifurcation region (around $16^{\circ} \mathrm{E}, 36^{\circ} \mathrm{N}$ ), and the northward branch of AIS east of Sicily are rather weak in the climatology (Fig. 11(a)), and well defined in the feature-oriented model initialization (Fig. 11(b)). When the prognostic model was initialized with the climatological field, the ensuing simulation resulted in unrealistic features and numerical instability in the eddy-rich regions east of Sicily. This indicates that the climatological fields need many in situ supporting observations in the region to result in a synoptic water mass and inertia fields for model initialization for short-term simulations (see Lermusiaux and Robinson, 2001). It also motivates the application of feature-oriented approach for synoptic forecasts.

\subsection{Dynamical simulations}

The synoptic initialization prepared by the FORMS approach in the strait of Sicily is used next in a dynamical simulation for model calibration. The dynamical model is the nonlinear primitive equation model of HOPS (Robinson, 1996). The numerical and physical parameters were chosen to be very similar to those of the original simulation by Lermusiaux (1999a,b). These are listed in Table 3. There are two important parameter differences that relate to using the feature model profiles as opposed to using available high-resolution in situ data sets. First, the open boundary conditions for the transport streamfunction and vorticity were chosen to be Spall and Robinson (1989) cFVn-like to maintain the continuity of the imposed AIS frontal system throughout the simulation. Second, the Rayleigh bottom friction

Table 3

Dynamical model parameters for strait of Sicily FORMS simulations

\begin{tabular}{ll}
\hline Numerical parameters & \\
Center of domain (latitude and longitude) & $36.25^{\circ} \mathrm{N}, 14^{\circ} \mathrm{W}$ \\
Domain extension & $630 \mathrm{~km}(x)$ by $459 \mathrm{~km}(y)$ \\
Horizontal grid resolution & $9 \mathrm{~km}$ \\
Grid size & $71(x), 52(y), 20$ (levels, double sigma) \\
Time step & $300 \mathrm{~s}$ \\
Physical parameters & \\
Shapiro filter & $F_{\mathrm{u}}, F_{\mathrm{v}}: 4,1,1 ; F_{\mathrm{t}}, F_{\mathrm{s}}: 4,1,1 ; F_{\mathrm{w}}: 2,1,1$ \\
Open boundary condition & $U, V:(\mathrm{ORI}) ;, S:(\mathrm{ORI}) ; \Psi, \omega:(\mathrm{cFVn})$ \\
Vertical mixing & $A_{\mathrm{v}}=0.5$ and $A_{\mathrm{v}}^{\mathrm{cvct}}=50 \mathrm{~cm}^{2} \mathrm{~s}^{-1} ; K_{\mathrm{v}}=0.1$ \\
& and $K_{\mathrm{v}}^{\mathrm{cvct}}=50 \mathrm{~cm}^{2} \mathrm{~s}-1$ \\
Drag coefficient & $C_{\mathrm{d}}=2.5 \times 10^{-3}$ \\
Rayleigh coastal friction & $\tau_{\mathrm{c}}=7200 \mathrm{~s}, L_{\mathrm{c}}=9 \mathrm{~km}$ \\
Rayleigh bottom friction & $\tau_{\mathrm{b}}=7200 \mathrm{~s}, H_{\mathrm{b}}=4$ bottom levels with $H_{\mathrm{b}} \leq 100 \mathrm{~m}$ \\
\hline
\end{tabular}



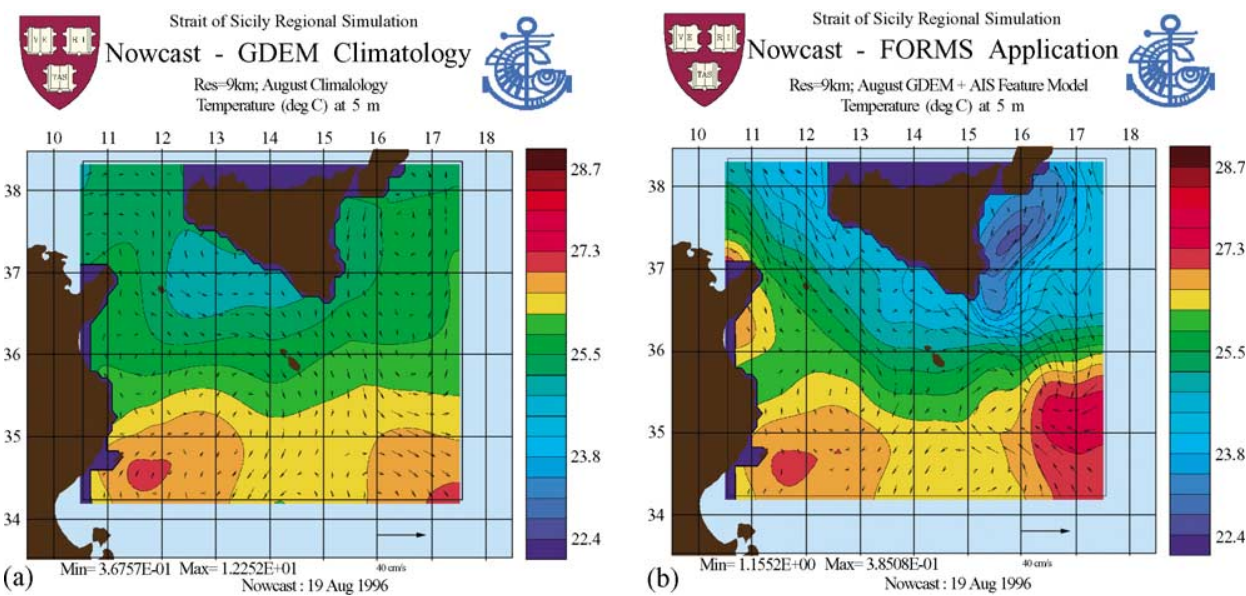

Fig. 11. Application of FORMS. Nowcast in the strait of Sicily region for 25 August 1996 as derived from monthly August climatology (a) and via feature-oriented methodology (b). The Nowcast in (b) is with AIS feature and background climatology only.

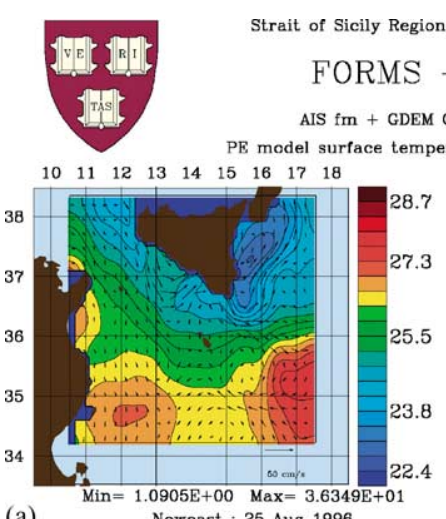

(a)

Nowcast : 25 Aug 1996

\section{- AIS}

\section{gy}

$\begin{array}{lllllllll}10 & 11 & 12 & 13 & 14 & 15 & 16 & 17 & 18\end{array}$

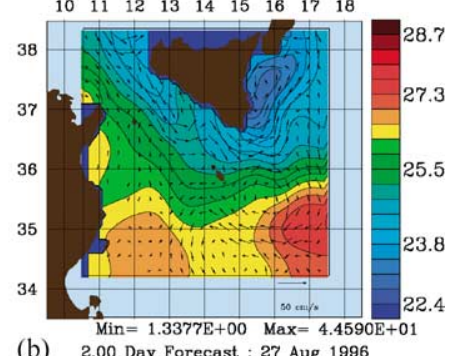

(b) 2.00 Day Forecast : 27 Aug 1996

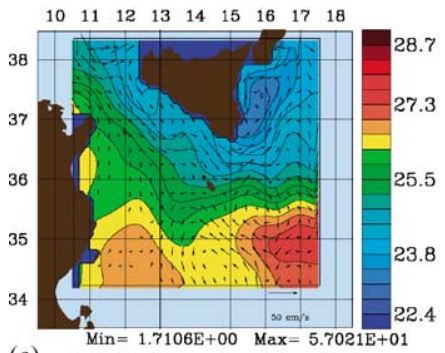

(c) 4.00 Day Forecast : 29 Aug 1996

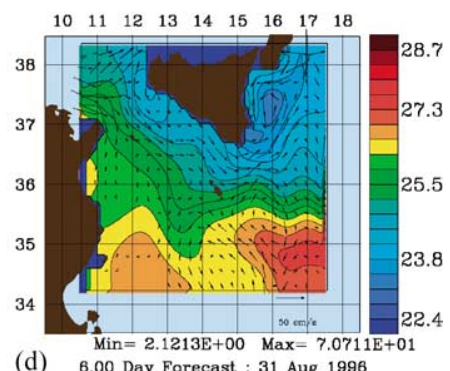

Fig. 12. FORMS in strait of Sicily: case I with AIS only. The week-long simulation is shown for Nowcast (a) and day 2 (b); day 4 (c); and day 6 (d). Note the weak dynamical evolution of the adventrure bank vortex (ABV) and the broad cyclonic flow east of Sicily. 
parameters which control possible numerical error growth in the barotropic transport and parameterize a simple bottom boundary layer for momentum needed special attention for maintaining a week-long stable simulation. The relaxation time $\left(\tau_{\mathrm{b}}\right)$ was increased to $7200 \mathrm{~s}$ from the Lermusiaux $(1999 \mathrm{a}, \mathrm{b})$ value of $3200 \mathrm{~s}$; and the Gaussian decay vertical-scale $H_{\mathrm{b}}$ was increased to four-levels (with $H_{\mathrm{b}} \leq 100 \mathrm{~m}$ ) from the original limit of two levels.

Three 1-week-long simulations using FORMS in the strait of Sicily illustrate how one can achieve a rapid and effective synoptic dynamics when all of the important synoptic features are included. First, we show the dynamical evolution with initialization using only a feature model AIS with climatology (Fig. 12). We then also add a data-based eddy feature model for ISV (Fig. 13) and finally another eddy feature model for ABV (Fig. 14).

One of the dynamical aspects of the first simulation (Fig. 12) is the tendency for formation of the $\mathrm{ABV}$, which is probably due to dynamical interaction between the AIS front, the coastal boundary and the underlying topography. This is evident in the turning of the along-shelf flow near $13.5^{\circ} \mathrm{E}, 37.2^{\circ} \mathrm{N}$ during days 2,4 and 6 (Fig. $12 \mathrm{~b}-\mathrm{d}$ ). The existence of this vortex has been previously linked to the topographic constraints in a dynamical study by Onken and Sellschopp (1988) in the region $12-14^{\circ} \mathrm{E}, 36-37.5^{\circ} \mathrm{N}$. This is also supported by the fact that the 7-day simulation presented in Fig. 12 was able to weakly reproduce the ABV by day 2 and maintain it throughout the simulation, although the initialization did not include this eddy feature explicitly. However, it is clear that prolonged dynamical simulation in this configuration will not lead to a stronger and robust ABV. This indicates the importance of inclusion of an ABV feature model to help generate realistic synoptic forecasts.

However, the ISV was not properly developed in the simulation presented in Fig. 12. The bifurcation region developed a cyclonic circulation east of Sicily and maintained this structure throughout the simulation. Thus, in addition to the AIS front, a simple data-based feature model for the ISV was constructed from the Lermusiaux and Robinson (2001) data set. The locations of these feature-oriented pseudo-observations are shown in Fig. 9(c). The initialization field generated by including both the AIS and ISV feature models was numerically integrated by the same model for 7 days, and the results are shown in Fig. 13. There is a distinct signature of the ISV around $36.5^{\circ} \mathrm{N}, 16^{\circ} \mathrm{E}$ in this simulation by day 2 .

A third and final simulation was carried out, which included all of the three feature models for the AIS, the ISV and the ABV (see Fig. 9(c) for the data-based feature model locations for $\mathrm{ABV}$ ). Note that the Nowcast now includes the vortices along with the fronts and the background climatology (Fig. 14a). As the simulation progresses, the two vortices adjust to the nonlinear dynamics of coastal and topographic interaction. The resulting fields on days 2, 4 and 6 as shown in Fig. 14b-d) indicate the strengthening and robustness of these features along with the meandering of the AIS frontal system and its bifurcation. Moreover, the final two simulations (Figs. 13 and 14) also show that the model evolution by day 4 extends the ISV southward and eastward, which is dynamically consistent with the results of Lermusiaux and Robinson (2001) simulations.

Comparison of the results of the three feature-oriented dynamical simulations above provides a basis for suggesting the following dynamical conclusions: (1) the underlying topography and coastal boundary plays a more dominant role for generation and maintenance of the ABV than for the ISV; (2) the dynamics of the ISV is more related to the internal baroclinic structure and variability of the water mass frontal system of the AIS and its bifurcation region near the ionian shelf. As an implication for operational oceanography, 

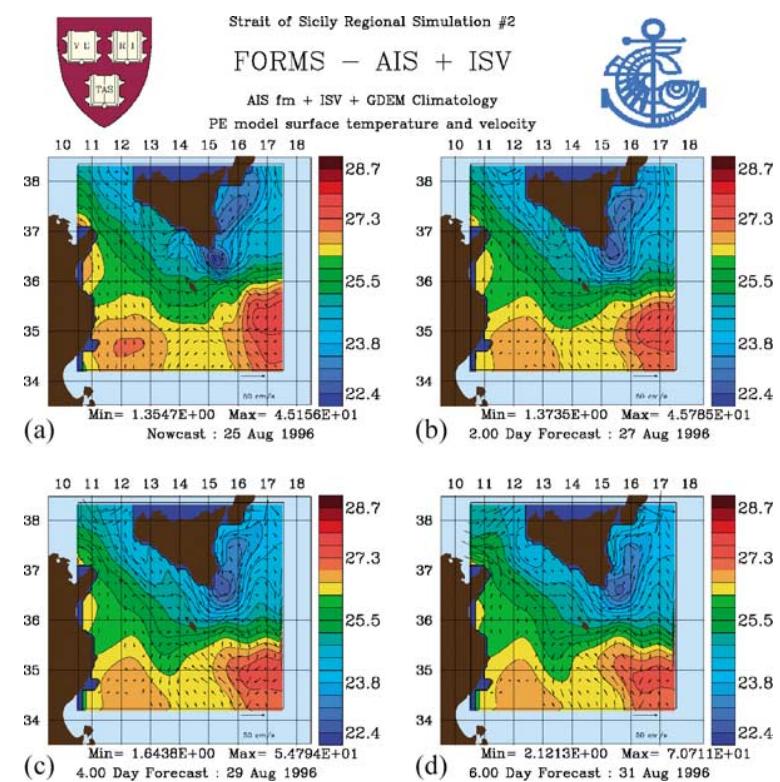

(d) $\begin{array}{r}\text { Min }=2.1213 \mathrm{E}+00 \text { Max }=7.0711 \\ 6.00 \text { Day Forecast : } 31 \text { Aug } 1996\end{array}$

(b) 2.00 Day Forecast ; 27 Aug 1996

Fig. 13. Application of FORMS in strait of Sicily: case II with AIS and ISV. The week-long simulation is shown for Nowcast (a) and day 2 (b); day 4 (c); and day 6 (d). Note the robustness of the ISV during the week-long simulation and its evolution in the southeast in contrast to the earlier simulation in case I (Fig. 12).

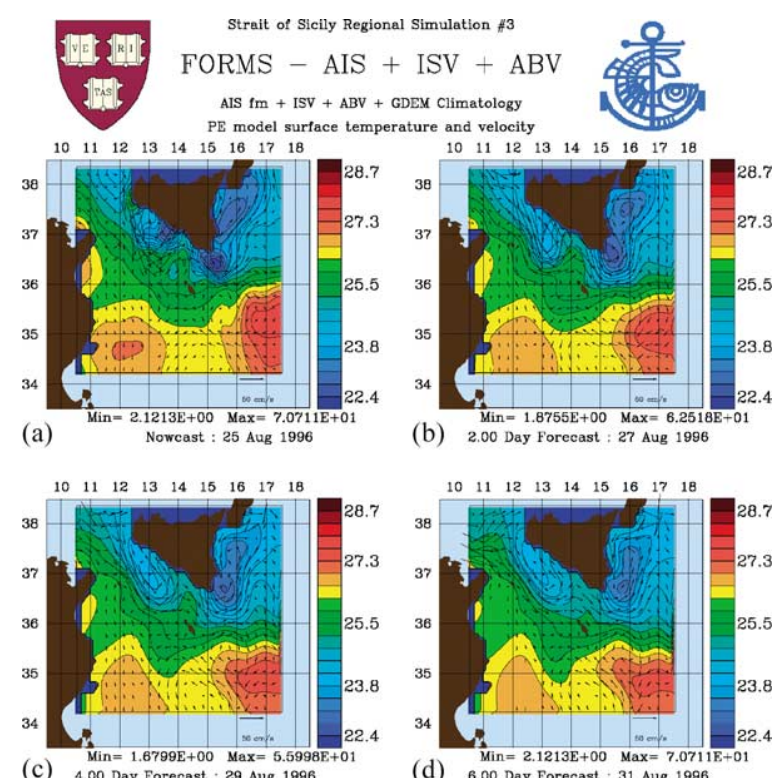

Fig. 14. Application of FORMS in strait of Sicily: case III with AIS, ISV and ABV. The week-long simulation is shown for Nowcast (a) and day 2 (b); day 4 (c); and day 6 (d). Note the robustness of both ABV and ISV during this week-long simulation in contrast to the earlier simulations in case I (Fig. 12) and case II (Fig. 13). 
where an efficient sampling strategy for a synoptic survey is critical, the collection of in situ data in the ISV region would be prioritized over that in the ABV region.

\section{Discussion and conclusion}

Previously developed forms of feature models in WNA for different types of fronts are presented in a generalized approach. The Gulf Stream frontal system is represented via velocity-based feature models; tidal fronts in Gulf of Maine are described by TSFMs with depth-varying tracer gradients; whereas a SSF is modeled by a melding function between two different water masses along and across a topographic gradient in the continental shelf region. A circular front such as eddies and gyres are included as integral part of any regional circulation system.

The steps for developing a feature-oriented regional modeling system can be summarized as follows: (1) the important dynamical features are identified in their synoptic state via satellite data; (2) the feature models for the fronts, eddies and gyres are strategically placed along and across their inferred locations; (3) an appropriate background climatology for the region is identified; (4) a comprehensive objective analysis of the temperature, salinity and dynamic height (with a prescribed level of no motion) fields which combines the synoptic feature model profiles and background climatology is carried out. These four steps will lead to a feature-oriented three-dimensional initialization field for the regional domain. A dynamical model can then be calibrated and validated with short- and long-term simulations. The stability and robustness of these simulations and sensitivity to both feature model and dynamical model parameters in a new regional ocean is a pre-requisite for operational forecasts.

It is apparent that many other oceanic regions in the world can be modeled in a featureoriented approach as outlined here. The classification of various fronts in the Global Coastal Ocean (Table 2) may be useful for future research. Note that every region is dynamically unique and certain parameters and characteristics may need to be modified to consider the local dynamical factors. Also, there are other types of fronts which are not yet modeled in a feature-oriented approach, such as coastal upwelling fronts (vertical velocity and winds are two important factors); equatorial jets and fronts, and eastern boundary currents and fronts.

The FORMS concept and methodology as presented is generic in nature. Although the presented simulations for GOMGB and strait of Sicily used the HOPS primitive equation model as the dynamical model, the approach is equally applicable and portable to other dynamical models. It is also anticipated that the dynamical concepts of FORMS will be expanded towards addressing the issues related to (i) dynamics of upper ocean; (ii) interaction with tides and waves; (iii) coastal upwelling; (iv) efficient adaptive sampling in combination with in situ data, satellite observations, historical sections and analytical structures in the future.

\section{Acknowledgements}

This work was supported by the NASA-AFMIS (Advanced Fisheries Management Information System) and NOPP-LOOPS (Littoral Ocean Observation Prediction System) projects at the University of Massachusetts Dartmouth and at Harvard University. Part of 
the work was also supported by ONR grants (N00014-95-1-0371 and N00014-95-1-0239) to Harvard University. We wish to thank the AFMIS and LOOPS scientists for their valuable help in discussion of development of ideas for this work. Special thanks are due to Dr. P.F.J. Lermusiaux and Mr. Wayne Leslie for their help with the strait of Sicily data and modeling discussions. We wish to thank professor Brian Rothschild for valuable discussions on the importance of generic feature models. Finally, we would like to thank two anonymous reviewers for their encouragement and comments to strengthen the text of the manuscript.

\section{Appendix A}

The analytical forms of the generic feature models are presented here. The feature models can be either velocity-based, or temperature/salinity-based. In both cases, one can use appropriate historical synoptic sections as substitutes for analytical feature models. These analytical/empirical data-based 'feature models' are placed along and across pre-defined or 'satellite-derived' locations of fronts, eddies and gyres.

1. The following form is used as a simple model for the three-dimensional velocity structure of a large-scale frontal system:

$$
u(x, y, z)=\gamma(y)\left\{\left[U^{\mathrm{T}}(x)-U^{\mathrm{B}}(x)\right] \phi(x, z)+U^{\mathrm{B}}(x)\right\}
$$

Here, $\gamma(y)$ is the non-dimensional horizontal velocity distribution with a value of unity at the jet axis; $\Phi(x, z)$ the non-dimensional vertical shear profile; $U^{\mathrm{T}}$ and $U^{\mathrm{B}}$ the top and the bottom velocities; while $x$ the dimensional downstream coordinate, $y$ the cross-stream coordinate (positive to the left of the flow) and $z$ is the dimensional vertical coordinate (positive upward).

2. The following form is used as a simple model for the temperature or salinity profile for a current/front/flow system:

$$
T(x, y, z)=T_{\mathrm{a}}(x, z)+\alpha(x, z) \Gamma(y)
$$

where

$$
T_{\mathrm{a}}(x, z)=\left\{\left[T_{0}(x)-T_{\mathrm{b}}(x)\right] \Phi(x, z)+T_{\mathrm{b}}\right\}
$$

Here, $\alpha(x, z)$ is the along-stream distribution of the cross-current slope of the tracer (temperature or salinity) representative of the across-feature spatial gradient, $\Gamma(y)$ the cross-frontal distribution of the tracer gradient $(\alpha)$; while $x$ the dimensional along-stream coordinate, $y$ the cross-stream coordinate with origin at the center of the current, $z$ the dimensional vertical coordinate (positive upward) and $\Phi(x, z)$ is the non-dimensional temperature/salinity profile.

3. The self-slop front tracer (temperature or salinity) distribution is modeled by

$$
T^{\mathrm{ss}}(x, y, Z)=T^{\mathrm{sh}}+\left(T^{\mathrm{sl}}-T^{\mathrm{sh}}\right) m(\eta, Z)
$$

where $m$ is the melding function:

$$
m(\eta, Z)=\frac{1}{2}+\frac{1}{2} \tanh \left[\frac{\eta-\theta \times Z}{\gamma}\right]
$$


where $\theta$ is the slope ( $\tan \alpha$ in Fig. 5a), $Z$ the depth, $\gamma$ the e-folding half-width of the front and $\eta$ is the cross-frontal distance.

4. The velocity-based eddy feature model is represented by

$$
\begin{aligned}
& v(r, z)=\frac{r}{r_{0}} V_{\mathrm{m}} \phi_{\mathrm{R}}(z) \exp \left(-\frac{t}{t_{0}}\right), \quad \text { for } 0 \leq r \leq r_{0} \\
& v(r, z)=V_{\mathrm{m}} \exp \left(a\left(\frac{1-r}{r_{0}}\right)\right) \phi_{\mathrm{R}}(z) \exp \left(-\frac{t}{t_{0}}\right), \quad \text { for } \quad r>r_{0}
\end{aligned}
$$

where $V_{\mathrm{m}}$ is the maximum azimuth velocity in the ring, $r_{0}$ the radius where $V_{\mathrm{m}}$ is reached, $\phi_{\mathrm{R}}(z)$ the vertical structure with baroclinic and barotropic components, $a$ a positive constant, $t$ the age of the eddy/ring and $t_{0}$ is an age attenuation scale.

5. The tracer (temperature and salinity) formulation for an eddy, or an warm/cold-core ring feature model is given by

$$
T(r, z)=T_{\mathrm{b}}(z)\left\{1-\exp \left(-\frac{r}{R}\right)\right\}+T_{\mathrm{c}}(z) \exp \left(-\frac{r}{R}\right)
$$

where $T_{\mathrm{b}}$ is the background tracer value and $T_{\mathrm{c}}$ is the core value. Typically, $R=5 R_{0}$, where $R_{0}$ is the Rossby radius. Note the fade-in, fade-out nature of the parameterization.

6. The velocity-based feature model for an elliptic gyre is given by

$$
\begin{aligned}
& u=u_{\mathrm{p}} \cos \theta-v_{\mathrm{p}} \sin \theta \\
& v=v_{\mathrm{p}} \cos \theta-u_{\mathrm{p}} \sin \theta
\end{aligned}
$$

where

$$
u_{\mathrm{p}}(r, z)=\gamma(r)\left[\left(U^{\mathrm{T}}-U^{B}\right) \Phi(z)+U^{\mathrm{B}}\right]
$$

and

$$
v_{\mathrm{p}}(r, z)=\gamma(r)\left[\left(V^{\mathrm{T}}-V^{\mathrm{B}}\right) \Phi(z)+V^{\mathrm{B}}\right]
$$

Please see Gangopadhyay et al. (1997) for more elaborate description.

7. The tracer (temperature and salinity) formulation for an elliptical gyre feature model is given by

$$
T(r, \theta, z)=T_{\mathrm{c}}(z) \alpha(\theta) \gamma(r)
$$

where $T_{\mathrm{c}}(z)$ is the vertical profile of temperature or salinity at the core of the gyre, $\alpha(\theta)$ is generally a delta or step function and $\gamma(r)$ is a linear or exponential function similar to (A.5) depending on the gyre characteristics.

\section{References}

Allen, J.S., Beardsley, R.C., Blanton, J.O., Boicourt, W.C., Butman, B., Coachman, L.K., Huyer, A., Kinder, T.H., Royer, T.C., Schumacher, J.D., Smith, R.L., Sturges, W., Winant, C.D., 1983. Physical oceanography of continental shelves. Rev. Geophys. Space Phys. 21, 1149-1181.

Behrens, W.J., Flagg, C.N., 1986. Shelf edge exchange processes. Phase I. Hydrography Report, July 1983-October 1984. Technical Report, Brookhaven National Laboratory. 
Belkin, I.M., Gordon, A.L., 1996. Southern ocean fronts from the Greenwich meridian to Tasmania. J. Geophys. Res. 101 (C2), 3675-3696.

Bisagni, J.J., 1991. Ocean surface topography measured by the Geosat radar altimeter during the frontal air-sea interaction experiment. J. Geophys. Res. 96, 22087-22099.

Blumberg, A.F., Mellor, G.L., 1987. A description of a three-dimensional coastal ocean circulation model, three-dimensional coastal ocean models. In: Heaps, N. (Ed.), American Geophysical Union, 208 pp.

Brink, K.H., 1998a. Deep-sea forcing and exchange processes. In: Brink, K.H., Robinson, A.R. (Eds.), The Sea, vol. 10. Wiley, New York, pp. 151-170.

Brink, K.H., 1998b. Wind-driven currents over the continental shelf. In: Brink, K.H., Robinson, A.R. (Eds.), The Sea, vol. 10. Wiley, New York, pp. 3-20.

Brown, W.S., 1998. Boundary flux measurements in the coastal ocean. In: Brink, K.H., Robinson, A.R. (Eds.), The Sea, vol. 10. Wiley, New York, pp. 399-418.

Brown, W.S., Bub, F.L., Rothschild, B.J., Sundermeyer, M.A., Gangopadhyay, A., Lane, R., Robinson, A.R., 2001. In: Proceedings of the ICES Annual Science Conference on Assimilating Near Real Time Fish and Environment Data into an Advanced Fisheries Management Information System, Oslo, Norway, 25-29 September.

Carter, E.F., Robinson, A.R., 1987. Analysis models for the estimation of oceanic fields. J. Atmos. Oceanic Technol. 4, 49-74.

Chapman, D.C., Gawarkiewicz, G., 1993. On the establishment of the seasonal pycnocline in the middle Atlantic bight. J. Phys. Oceanogr. 23, 2487.

Church, J.A., Bethoux, J.-P., Theocharis, A., 1998. Semienclosed seas, islands and Australia (S). In: Robinson, A.R., Brink, K.H. (Eds.), The Sea, vol. 11. Wiley, New York, pp. 79-124.

Cummings, J.A., Szczechowski, C., Carnes, M., 1997. Global and regional ocean thermal analysis systems. Marine Tech. Soc. J. 31, 63-75.

De Agostini Institute, 1998. Atlante geografico metodico de Agostini. Officine Grafiche de Agostini, Novana, 272 pp.

Fox, D.N., Carnes, M.R., Mitchell, J.L., 1992. Characterizing major frontal systems: a Nowcast/forecast system for northwest Atlantic. Oceanography 5 (1), 49-53.

Gangopadhyay, A., Robinson, A.R., 1997. Circulation and dynamics of the western north Atlantic. III. Forecasting the meanders and rings. J. Atmos. Oceanic Technol. 14 (6), 1352-1365.

Gangopadhyay, A., Robinson, A.R., Arango, H.G., 1997. Circulation and dynamics of the western north Atlantic. I. Multiscale feature models. J. Atmos. Oceanic Technol. 14 (6), 1314-1332.

Gangopadhyay, A., Robinson, A.R., Haley, P.J., Leslie, W.G., Lozano, C.J., Bisagni, J.J., Yu, Z., 2002. Feature oriented regional modeling and simulation (FORMS) in Gulf of Maine and Georges Bank. Continental Shelf Res.

Glenn, S.M., Robinson, A.R., 1995. Validation of an operational Gulf Stream forecasting model. In: Qualitative Skill Assessment for Coastal Models, AGU Estuarine/Coastal Series, vol. 47. American Geophysical Union, pp. 469-499.

Gordon, A.L., 1986. Interocean exchange of thermocline water. J. Geophys. Res. 91 (C4), 5037-5046.

Grancini, G.F., Michelato, A., 1987. Current structure and variability in the strait of Sicily and adjacent area. Ann. Geophys. Ser. B, Terrestrial Planet. Phys. 5 (1), 75-88.

Haidvogel, D.B., Beckmann, A., 1998. Numerical models of the coastal ocean. In: Brink, K.H., Robinson, A.R. (Eds.), The Sea, vol. 10. Wiley, New York, pp. 457-482.

Haidvogel, D.B., Arango, H.G., Hedstrom, K., Beckmann, A., Malanotte-Rizzoli, P., Shchepetkin, A.F., 2000. Model evaluation experiments in the north Atlantic basin: simulations in nonlinear terrain-following coordinates. Dynamics Atmos. Oceans 32 (3/4), 239-281.

Halkin, D., Rossby, H.T., 1985. The structure and transport of the Gulf Stream at 73W. J. Phys. Oceanography 15 , 1439-1452.

Halliwell Jr., G.R., Mooers, C.N.K., 1979. The space time structure and variability of the shelf water and Gulf Stream surface temperature fronts and associated warm-core eddies. J. Geophys. Res. 84, 7707-7725.

Hallock, Z.R., Teague, W.J., Hurlburt, H.E., 1996. A deep western boundary current in the north Pacific. Naval Res. Lab. Rep. 2 (C3), 45-55.

Hannah, C.G., Shore, J.A., Loder, J.W., Naimie, C.E., 2001. Seasonal circulation on the western and central Scotian shelf. J. Phys. Oceanogr. 31 (2), 591-615. 
Heathershaw, A.D., Foreman, S.J., 1996. FOAM - a forecasting ocean-atmosphere model for naval applications. J. Defence Sci. 1, 434-438.

Hill, A.E., 1998. Buoyancy effects in coastal and shelf seas. In: Brink, K.H., Robinson, A.R. (Eds.), The Sea, vol. 10. Wiley, New York, pp. 21-62.

Hill, A.E., Hickey, B.M., Shillington, F.A., Strub, P.T., Brink, K.H., Barton, E.D., Thomas, A.C., 1998. Eastern ocean boundaries (E). In: Robinson, A.R., Brink, K.H. (Eds.), The Sea, vol. 11. Wiley, New York, pp. $29-68$.

Horne, E.P.W., Loder, J.W., Harrison, W.G., Mohn, R., Lewis, M.R., Irwin, B., Platt, T., 1989. Nitrate supply and demand at the Georges Bank tidal front. Bulletin of Marine Science 532-3, 145-158.

Houghton, R.W., Aikman III, F., Ou, H.W., 1988. Shelf-slope frontal structure and cross-shelf exchange at the New England shelf-break. Continental Shelf Res. 8, 687-710.

Houghton, R.W., Flagg, C.N., Pietrafesa, L.J., 1994. Shelf-slope water frontal structure, motion and eddy heat flux in the southern middle Atlantic bight. Deep Sea Res. 41 (II), 273-306.

Hurlburt, H.E., Fox, D.N., Metzger, E.J., 1990. Statistical inference of weakly correlated sub-thermocline fields from altimeter data. J. Geophys. Res. 95 (C7), 11375-11409.

Hurlburt, H.E., Wallcraft, A.J., Schmitz Jr., W.J., Hogan, P.J., Metzger, E.J., 1996. Dynamics of the Kuroshio/Oyashio current system using eddy-resolving models of the north Pacific Ocean. J. Geophys. Res. 101, 941-976.

Jilan, S., 1998. Circulation dynamics of the China seas north of $18 \mathrm{~N}$ (12, S). In: Robinson, A.R., Brink, K.H. (Eds.), The Sea, vol. 11. Wiley, New York, pp. 483-506.

Johns, T.C., Carnel, R.E., Crossley, J.F., Gregory, J.M., Mitchell, J.F.B., Senior, C.A., Tett, S.F.B., Wood, R.A., 1997. The second Hadley centre coupled ocean-atmosphere GCM: model description, spinup and validation. Climate Dynamics 13, 103-134.

Lermusiaux, P.F.J., 1999a. Estimation and study of mesoscale variability in the strait of Sicily. Dynamics Atmos. Oceans 29, 255-303.

Lermusiaux, P.F.J., 1999b. Data assimilation via error subspace statistical estimation. Part II. Mid-Atlantic bight shelfbreak front simulations and ESSE validation. Mon. Wea. Rev. 127 (8), 1408-1432.

Lermusiaux, P.F.J., Robinson, A.R., 2001. Features of dominant mesoscale variability, circulation patterns and dynamics in the strait of Sicily. Deep Sea Res. 48 (I), 1953-1997.

Linder, C.A., Gawarkiewicz, G., 1998. A climatology of the shelfbreak front in the middle Atlantic bight. J. Geophys. Res. 103 (C9), 18405-18424.

Loder, J.W., Petrie, B., Gawarkiewicz, G., 1998. The coastal ocean off northeastern North America: a large-scale view (1, W). In: Robinson, A.R., Brink, K.H. (Eds.), The Sea, vol. 11. Wiley, New York, pp. 125-134.

Loder, J.W., Boicourt, W.C., Simpson, J.H., 1998. Western ocean boundary shelves (W). In: Robinson, A.R., Brink, K.H. (Eds.), The Sea, vol. 11. Wiley, New York, pp. 3-28.

Lozano, C.J., Robinson, A.R., Arango, H.G., Gangopadhyay, A., Sloan, N.Q., Haley, P.J., Leslie, W.G., 1996. An interdisciplinary ocean prediction system: assimilation strategies and structured data models. In: Malanotte-Rizzoli, P. (Ed.), Modern Approaches to Data Assimilation in Ocean Modelling. Elsevier Oceanography Series, Elsevier, The Netherlands, pp. 413-452.

Lynch, D.R., 1999. A review of modeling in the Gulf of Maine. Naval Res. Rev. 61 (1).

Lynch, D.R., Ip, J.T.C., Naimie, C.E., Werner, F.E., 1996. Comprehensive coastal circulation model with application to the Gulf of Maine. Continental Shelf Res. 16, 875-906.

Manzella, G.M.R., Gasparini, G.P., Astraldi, M., 1988. Water exchange between the eastern and western Mediterranean through the strait of Sicily. Deep Sea Res. 35, 1121-1135.

Mountain, D.G., 1991. The volume of shelf water in the middle Atlantic bight: seasonal and interannual variability, 1977-1987. Continental Shelf Res. 11, 251-267.

Onken, R., Sellschopp, J., 1988. Seasonal variability of flow instabilities in the strait of Sicily. J. Geophys. Res. 103 (C11), 24,799-24,820.

Piccolo, M.C., 1998. Oceanography of the western south Atlantic continental shelf from 33 to $55^{\circ} \mathrm{S}(5$, W). In: Robinson, A.R., Brink, K.H. (Eds.), The Sea, vol. 11. Wiley, New York, pp. 253-272.

Preller, R.H., Hogan, P.J., 1998. Oceanography of the sea of Okhotsk and the Japan/east sea (11, S). In: Robinson, A.R., Brink, K.H. (Eds.), The Sea, vol. 11. Wiley, New York, pp. 429-482.

Ramp, S.R., Schlitz, R.J., Wright, W.R., 1985. The deep flow through the Northeast Channel, Gulf of Maine. J. Phys. Oceanog. 15, 1790-1808. 
Robinson, A.R., 1996. Forecasting and simulating coastal ocean processes and variabilities with the Harvard ocean prediction system, coastal ocean processes. In: Mooers, C.N.K. (Ed.), Coastal and Estuarine Studies, AGU, pp. 77-100.

Robinson, A.R., 1999. Realtime forecasting of the multidisciplinary coastal ocean with the littoral ocean observing and predicting system (LOOPS). In: Proceedings of the Preprint Volume of the Third Conference on Coastal Atmospheric and Oceanic Prediction and Processes, 3-5 November 1999, New Orleans, LA. American Meteorological Society, Boston, MA.

Robinson, A.R., Gangopadhyay, A., 1997. Circulation and dynamics of the western north Atlantic. II. Dynamics of meanders and rings. J. Atmos. Oceanic Technol. 14 (6), 1333-1351.

Robinson, A.R., Brink, K.H., (Eds.), 1998. The sea, Vol. 11. Wiley, New York, pp. 1062.

Robinson, A.R., Glenn, S.M., 1999. Adaptive sampling for ocean forecasting. Naval Res. Rev. 51 (2), $28-38$.

Robinson, A.R., Sellschopp, J., 2001. Rapid assessment of the coastal ocean environment. In: Pinardi, Woods (Eds.), Ocean Forecasting: Conceptual Basis and Application. Springer, Berlin, pp. 203-232.

Robinson, A.R., Spall, M.A., Pinardi, N., 1988. Gulf Stream simulaitons and the dynamics of ring and meander processes. J. Phys. Oceanogr. 18, 1811-1853.

Robinson, A.R., Glenn, S.M., Spall, M.A., Walstad, L.J., Gardner, G.M., Leslie, W.G., 1989. Forecasting meanders and rings. EOS Oceanogr. Rep. 70 (45), 1464-1473.

Robinson, A.R., Golnaraghi, M., Leslie, W.G., Artegiani, A., Hecht, A., Lazzoni, E., Michelato, A., Sansone, E., Theocharis, A., Unluata, U., 1991. The eastern Mediterranean general circulation: features, structure and variability. Dynamics Atmos. Oceans 15 (3-5), 215-240.

Robinson, A.R., Lermusiaux, P.F.J., Sloan III, N.Q., 1998. Data assimilation. In: Brink, K.H., Robinson, A.R. (Eds.), The Sea, vol. 10. Wiley, New York, pp. 541-594.

Robinson, A.R., Rothschild, B.J., Leslie, W.G., Bisagni, J.J., Borges, M.F., Brown, W.S., Cai, D., Fortier, P., Gangopadhyay, A., Haley Jr., P.J., Kim, H.S., Lanerolle, L., Lermusiaux, P.F.J., Lozano, C.J., Miller, M.G., Strout, G., Sundermeyer, M.A., 2000. In: Proceedings of the AMS Annual Meeting on the Development and Demonstration of an Advanced Fisheries Management Information System, January 2001.

Royer, T.C., Stabeno, P.J., 1998. Polar ocean boundaries (P). In: Robinson, A.R., Brink, K.H. (Eds.), The Sea, vol. 11. Wiley, New York, pp. 69-78.

Sainz-Trapaga, S., Sugimoto, T., 2000. Three-dimensional velocity field and cross-frontal water exchange in the Kuroshio extension. J. Oceanogr. 56, 79-92.

Sheppard, C.R., Dixon, D.J., 1998. Seas of the Arabian region (29, S). In: Robinson, A.R., Brink, K.H. (Eds.), The Sea, vol. 11. Wiley, New York, pp. 915-932.

Shetye, S.R., Gouveia, A.D., 1998. Coastal circulation in the north Indian Ocean (14, S-W). In: Robinson, A.R., Brink, K.H. (Eds.), The Sea, vol. 11. Wiley, New York, pp. 523-556.

Simpson, J.H., 1998. Tidal processes in shelf seas. In: Brink, K.H., Robinson, A.R. (Eds.), The Sea, vol. 10. Wiley, New York, pp. 113-150.

Simpson, J.H., Hunter, J.R., 1974. Fronts in the Irish Sea. Nature 250, 404-406.

Sloan III, N.Q., 1996. Dynamics of a shelf-slope front: process studies and data-driven simulations in the middle Atlantic bight. Ph.D. thesis, Harvard University, Cambridge, MA, USA.

Spall, M.A., Robinson, A.R., 1989. A new open ocean, hybrid coordinate primitive equation model. Math. Comput. Simulation 31, 241-269.

Spall, M.A., Robinson, A.R., 1990. Regional primitive equation studies of the Gulf Stream meander and ring formation region. J. Phys. Oceanogr. 20 (7), 905-1016.

Teague, W.J., Carron, M.J., Hogan, P.J., 1990. A comparison between the generalized digital environmental model and Levitus climatologies. J. Geophys. Res. 95 (C5), 7167-7183.

Teague, W.J., Shiller, A.M., Hallock, Z.R., 1994. Hydrographic section across the Kuroshio near 35N, 143E. J. Geophys. Res. 99 (C4), 7639-7650.

Theocharis, A., Gacic, M., Kontoyiannis, H., 1998. Physical and dynamical processes in the coastal and shelf areas of the Mediterranean. In: Robinson, A.R., Brink, K.H. (Eds.), The Sea, vol. 11. Wiley, New York, pp. 863-887.

Warn-Varnas, A., Sellschopp, J., Haley Jr., P.J., Leslie, W.G., Lozano, C.J., 1999. Strait of Sicily water masses. Dynamics Atmos. Oceans 29, 437-469.

Watts, D.R., Tracy, K.L., Friedlander, A.I., 1989. Producing accurate maps of the Gulf Stream thermal front using objective analysis. J. Geophys. Res. 94, 8040-8052.

Wright, W.R., 1976. The limits of shelf water south of cape cod, 1941 to 1972. J. Marine Res. 34, 1-14. 